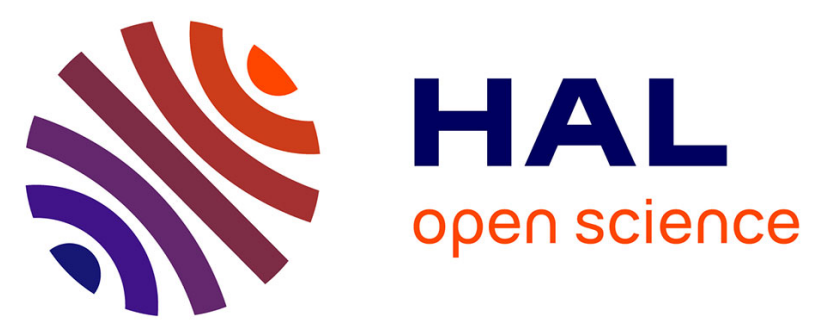

\title{
22-kyr-Long Record of Surface Faulting Along the Source of the 30 October 2016 Earthquake (Central Apennines, Italy), From Integrated Paleoseismic Data Sets
}

F.R. Cinti, P.M. de Martini, D. Pantosti, S. Baize, A. Smedile, F. Villani, R. Civico, S. Pucci, A.M. Lombardi, V. Sapia, et al.

\section{To cite this version:}

F.R. Cinti, P.M. de Martini, D. Pantosti, S. Baize, A. Smedile, et al.. 22-kyr-Long Record of Surface Faulting Along the Source of the 30 October 2016 Earthquake (Central Apennines, Italy), From Integrated Paleoseismic Data Sets. Journal of Geophysical Research: Solid Earth, 2019, 124 (8), pp.9021-9048. 10.1029/2019JB017757 . hal-02524794

\section{HAL Id: hal-02524794 \\ https://hal.science/hal-02524794}

Submitted on 10 Dec 2021

HAL is a multi-disciplinary open access archive for the deposit and dissemination of scientific research documents, whether they are published or not. The documents may come from teaching and research institutions in France or abroad, or from public or private research centers.
L'archive ouverte pluridisciplinaire HAL, est destinée au dépôt et à la diffusion de documents scientifiques de niveau recherche, publiés ou non, émanant des établissements d'enseignement et de recherche français ou étrangers, des laboratoires publics ou privés. 


\author{
RESEARCH ARTICLE \\ 10.1029/2019JB017757 \\ Key Points: \\ - We integrate paleoseismic datasets \\ along the Mt. Vettore-Mt. Bove \\ normal fault system rupturing on 30 \\ October 2016, M6.5, Norcia \\ Earthquake \\ - Seven surface faulting events \\ ruptured the Mt. Vettore-Mt. Bove \\ fault system in the past $-22 \mathrm{kyr}$ \\ - Paleoseismologic slip rates, \\ recurrence intervals, and rupture \\ scenarios contribute to the \\ understanding of seismogenic \\ processes in central Apennines
}

Supporting Information:

- Supporting Information S1

Correspondence to:

F. R. Cinti,

francesca.cinti@ingv.it

Citation:

Cinti, F. R., De Martini, P. M., Pantosti, D., Baize, S., Smedile, A., Villani, F., et al. (2019). 22-kyr-long record of surface faulting along the source of the 30 October 2016 earthquake (central Apennines, Italy), from integrated paleoseismic data sets. Journal of Geophysical Research: Solid Earth, 124 https://doi.org/10.1029/2019JB017757

Received 1 APR 2019 Accepted 24 JUL 2019 Accepted article online 31 JUL 2019

(c)2019. American Geophysical Union. All Rights Reserved.

\section{2-kyr-Long Record of Surface Faulting Along the Source of the 30 October 2016 Earthquake (Central Apennines, Italy), From Integrated Paleoseismic Data Sets}

\author{
F. R. Cinti ${ }^{1}$ (D) P. M. De Martini ${ }^{1}$ (D) D. Pantosti ${ }^{1}$ (D) S. Baize ${ }^{2}$ (D) A. Smedile ${ }^{1}$ (D) F. Villani ${ }^{1}$ (D),

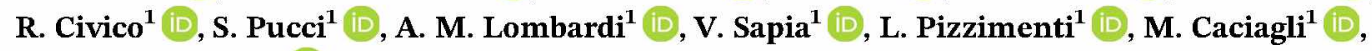 \\ and C. A. Brunori ${ }^{1}$ (D) \\ ${ }^{1}$ Istituto Nazionale di Geofisica e Vulcanologia, Italy, ${ }^{2}$ Institut de Radioprotection et de Sûreté Nucléaire, Paris, France
}

\section{Introduction}

The 2016 earthquake sequence in the central Apennines (main events on 24 August Mw 6.1, 26 October Mw 5.9, and 30 October Mw 6.5; Figure 1) took the lives of 299 people, severely injured 365 others, and caused severe damage to structures and infrastructures and to a particularly rich cultural heritage, resulting in 50,000 displaced persons and more than $10 \mathrm{~B} €$ losses (http://www.protezionecivile.gov.it/risk-activities/seismic-risk/emergencies/central-italy-2016). This sequence followed by 7 years the L'Aquila earthquake, located about $40 \mathrm{~km}$ to the south, and by 19 years the Umbria-Marche sequence located about $35 \mathrm{~km}$ to the northwest, so that it appears to fill a gap of seismicity (Figure S1 in the supporting information). The largest mainshock of the 2016 sequence was the Mw 6.5 Norcia earthquake of 30 October, the largest event in Italy since the $1980 \mathrm{Mw} 6.9$ Irpinia earthquake. A wealth of coseismic geological data for the three events of the sequence was collected and analyzed (e.g., Civico et al., 2018, and references therein; EMERGEO Working Group, 2016, 2017a, 2017b) along with seismological, geodetic, and geophysical observations (e.g., Cheloni et al., 2017; Chiaraluce et al., 2017; Scognamiglio et al., 2018). In general, those multidisciplinary works point out a substantial consistency in the description and understanding of the 2016 seismic sources. Given the amount and high quality of data available, especially for the Norcia earthquake, we believe this represents a unique chance to undertake new paleoseismological investigations on the earthquake fault, known as the Mt. Vettore-Mt. Bove fault system, and hereinafter referred as VBFS (Pierantoni et al., 2013, and references therein). The goal is to understand the long-term seismic behavior of the earthquake fault, date the previous surface faulting events, and frame these results within the earthquake history of this sector of central Italy. In the area, historical, archeoseismological, and paleoseismological data clearly testify the occurrence of moderate to large earthquakes in the past. The 1703 earthquake sequence (three events within 2 weeks with local intensity up to 10 MCS, Guidoboni et al., 2018), the 1997 Colfiorito earthquake sequence (three events within 2 months with Mw up to 6.1; Chiaraluce et al., 2003), and the $2009 \mathrm{Mw} 6.1$ L'Aquila earthquake (Chiaraluce et al., 2011) severely hit the broad region (Figure S1). None of the 2016 mainshocks occurred on seismogenic faults responsible for these historical and modern events. 


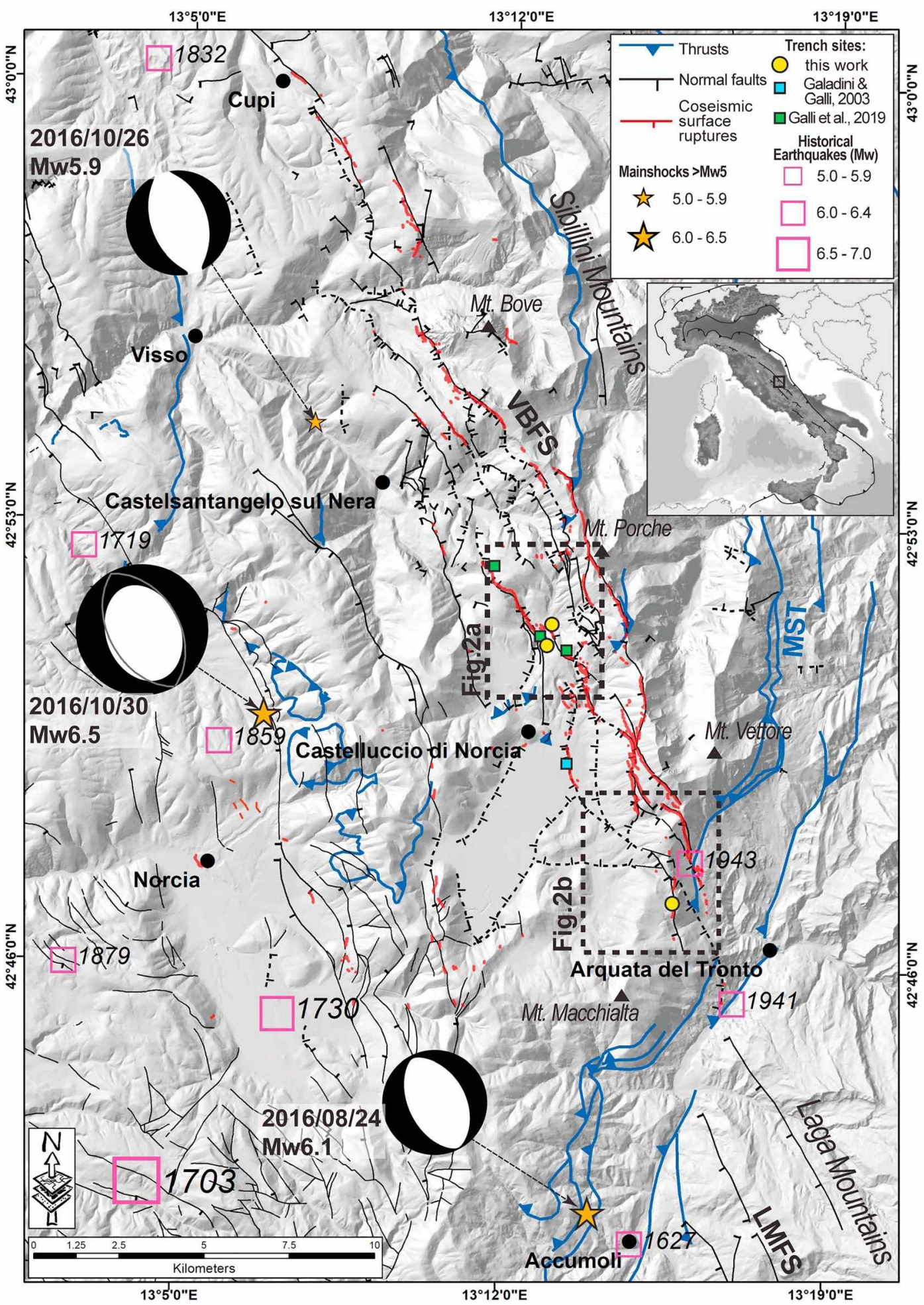

Figure 1. Simplified structural map of the area struck by the 2016-2017 seismic sequence (compiled from 1:10,000-scale cartography of Regione Umbria and Marche, Centamore et al., 1992, and Pierantoni et al., 2013). The labels VBFS and LMFS indicate the Mt. Vettore-Mt. Bove and Laga Mts. fault systems, respectively. MST indicates the Sibillini Mts. thrust. The pink open squares indicate the main historical seismic events (Guidoboni et al., 2018). The time domain moment tensor solutions of the Mw 6.5 mainshock on 30 October 2016 and of the two other mainshocks on 24 August and 26 October are from Scognamiglio et al. (2018), Tinti et al. (2016), and Chiaraluce et al. (2017), respectively. The trace of the coseismic surface ruptures produced by the three mainshocks (in red) is from Civico et al. (2018). The location of the three trenches performed in this work is marked with yellow circles. Trenching sites from other works are indicated with green squares (three trenches by Galli et al., 2019) and blue squares (three trenches at the same site by Galadini \& Galli, 2003). 
Several paleoseismological and archeoseismological investigations have been performed to extend back in time the record of seismicity in the area, to date paleo-earthquakes, and to establish slip rates and average recurrence times; these latter amount to $\leq 1 \mathrm{~mm} /$ year and several centuries to millennia for $\mathrm{M}>6$ earthquakes, respectively (e.g., Blumetti et al., 2017; Cinti et al., 2011; Gori et al., 2011; Michetti et al., 1996; Moro et al., 2016; Pantosti et al., 1996; Salvi et al., 2003).

The Norcia earthquake represents the only case in Italy that ruptured a fault splay that was previously studied by trenching (Galadini \& Galli, 2003). This study concluded that the VBFS was a silent fault in recent history, with the potential for M 6.5 earthquakes, the most recent of which dated after 4,155-3,965 years BP and before the sixth-seventh centuries CE. Retrospectively, this was concordant with the activation of the VBFS on 30 October 2016. The surface rupturing 2016 Norcia earthquake represents the chance to extend the earthquake history of the VBFS, refine the slip rate and other parameters that are important to assess the seismic hazard in this part of the Apennines. We took this opportunity and investigated new trenches along two distinct segments of the VBFS. The results and analysis are presented in this work. Here we also compare and integrate the previous trenching data from Galadini and Galli(2003) and the contemporary data from Galli et al. (2019) along the same fault system, thus performing a complete analysis of the overall paleoseismic data set published so far on the fault that caused the 2016 earthquake. Indeed, it is worth noting that the 2016 earthquake represents a rare surface faulting event in Italy and an unprecedented case of coseismic rupture trace mapped in detail and trenched with a total of nine excavations. Six out of nine trenches were dug after the Mw 6.5 event (maximum trench distance of $10 \mathrm{~km}$ ) across three distinct splays of the system (Figure 1; fault splays coded as PRA1, PRA2, VET1, and VET6 splays in Villani et al., 2018), where high values of coseismic slip at depth occurred (Scognamiglio et al., 2018).

Knowing the ancestors of the 2016 events from paleoseismology can help not only in extending back in time the catalog of historical seismicity but also in linking known historical earthquakes to the causative faults, which in turn helps in understanding the seismogenic setting, for example, fault interactions or event clustering in time and space, which appear to be common in this area (Figure S1). Thus, this work represents also a geological contribution to time-dependent hazard models of large earthquakes in probabilistic seismic hazard analyses.

In the following, we shortly introduce the 2016 earthquake sequence and the Mw 6.5, 30 October 2016 coseismic effects at the surface. Then, we address four primary topics: (1) the presentation of our paleoseismic record on the VBFS, discussing selection of the trench sites, trench observations, and earthquake timing; (2) the integration of our results with the multiple fault-trench investigations from other authors to reduce uncertainties in earthquake chronologies; (3) the estimation of slip rate and average earthquake recurrence, fundamental components of our understanding of the VBFS activity; and (4) the implications of our synthesis of VBFS paleoseismic data for the broad understanding of the seismogenic source within the Apennines tectonic frame, including earthquake rupture models.

\section{The 2016 Surface Faulting and Implications for Paleoseismology}

The 2016 earthquake sequence in the central Apennines (Figure 1) started on 24 August with a Mw 6.1 mainshock (referred to as the Amatrice earthquake), which was followed by a Mw 5.9 mainshock on 26 October (referred to as the Visso earthquake) and a Mw 6.5 mainshock on 30 October 2016 (referred to as the Norcia earthquake). The epicenters of the two latter events were located 25 and $19 \mathrm{~km}$ to the northwest of the Amatrice one, respectively (Figure 1). Overall, these three events activated a rupture area about $80 \mathrm{~km}$ long and $20 \mathrm{~km}$ wide, well pictured by the aftershock distribution (Figure S1; Chiaraluce et al., 2017, and references therein). The three mainshocks show the typical characteristics of this portion of the central Apennines: shallow seismogenic thickness $(5-15 \mathrm{~km})$ and normal faulting occurring on NW to NNW striking, prevalently SW dipping fault systems. These earthquakes respond to the NE directed extensional regime acting since the Late Pliocene-Pleistocene, which is coupled with regional uplift of the central Apennines (e.g., D'Anastasio et al., 2006; Montone et al., 2012; Figure 1). The 2016 sequence occurred on the NNW striking, SW dipping VBFS and produced surface faulting characterized by dominant $\mathrm{SW}$ facing, $\sim \mathrm{N} 155^{\circ}$ striking scarps, with lengths and throws proportional to the individual event magnitudes (Villani, Civico, et al., 2018; Villani, Pucci, et al., 2018, and references therein; Figure S2). The Amatrice earthquake produced a continuous $~ 5.2-\mathrm{km}$-long rupture with an average displacement of $0.13 \mathrm{~m}$ (EMERGEO Working Group, 2016; 


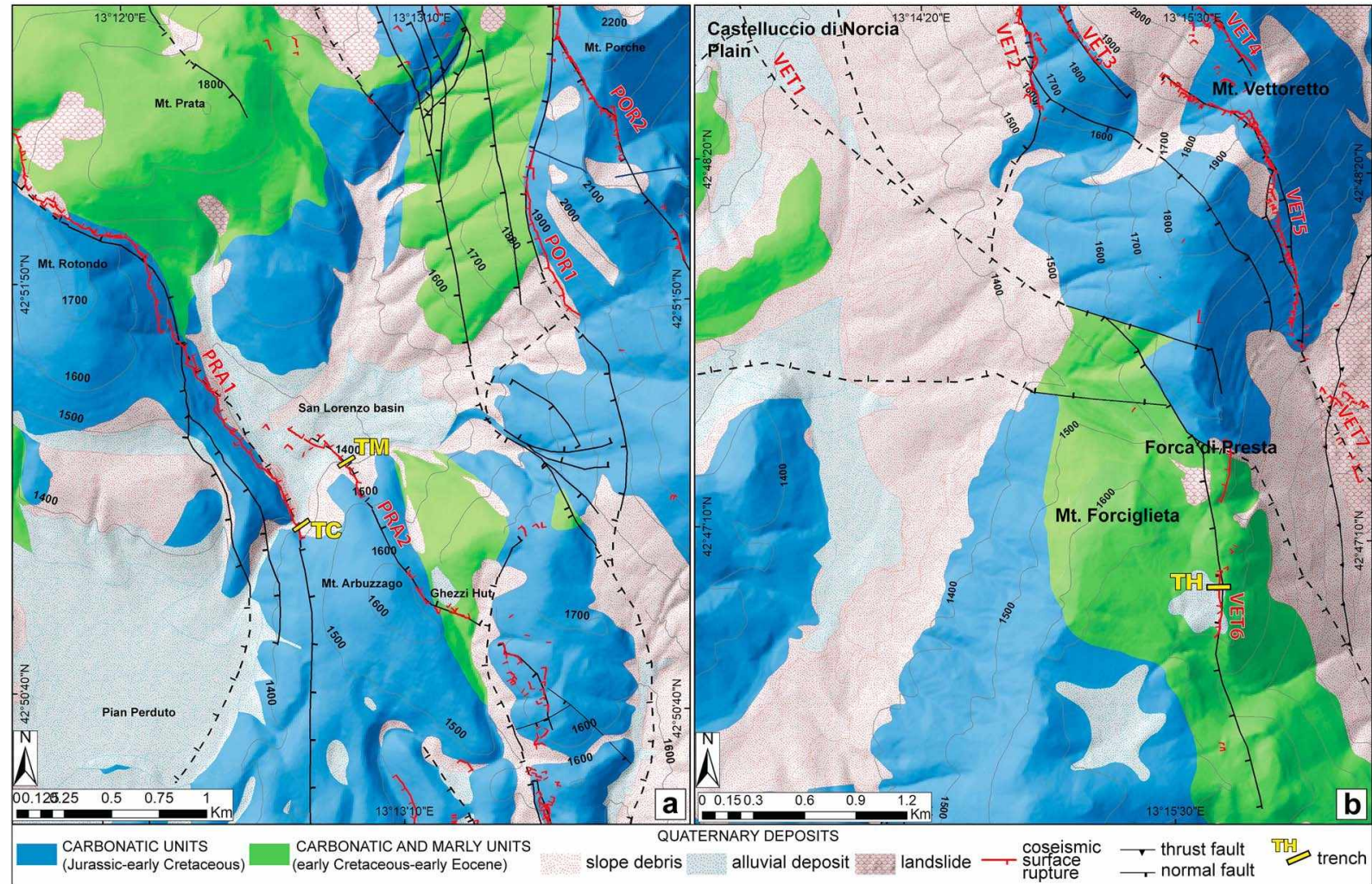

Figure 2. Simplified geological map (modified from 1:10,000-scale cartography of Regione Umbria and Marche and Pierantoni et al., 2013) of the (a) San Lorenzo site and surrounding area, showing the Mt. Rotondo and San Lorenzo-Ghezzi antithetic coseismic surface ruptures (in red; yellow rectangles are the location of the Curly [TC] and Matthew [TM] trenches), and (b) Forca di Presta site and surrounding area, showing the southern Vettore-Forciglieta coseismic surface ruptures (in red; yellow rectangle is the location of the Hope trench [TH]). Labels of the fault splays are also reported as in Villani, Pucci, et al. (2018).

Pucci et al., 2017). The Visso earthquake produced a discontinuous surface rupture with a length estimated from a minimum of $7 \mathrm{~km}$ (Villani, Pucci, et al., 2018), up to $\sim 12 \mathrm{~km}$ (Walters et al., 2018), and with an average displacement of $0.11 \mathrm{~m}$. The rupture length of this event is debated as it was mapped with lower detail and completeness with respect to the other two quakes, due to the very limited time before the following largest Norcia event (Figure S2). The Norcia event overprinted and magnified surface ruptures from the two previous mainshocks, thus producing as a whole a nearly 28-km-long surface rupture with average dip slip of $0.45 \mathrm{~m}$ that frequently exceeded $1 \mathrm{~m}$ and a maximum peak of $2.1 \mathrm{~m}$ in the 2-km-long section running along the Mt. Vettore slope in the southern portion of the rupture (Brozzetti et al., 2019; EMERGEO Working Group, 2017a, 2017b; Villani, Civico, et al., 2018; Villani, Pucci, et al., 2018; Figure 1). Measurements of the near-field coseismic displacement associated with the 30 October 2016 earthquake using low-cost Global Navigation Satellite System (GNSS) receivers located in the footwall and hanging wall of the VBFS, close to the surface rupture (Wilkinson, 2017), highlighted the occurrence of surface faulting as a direct effect of the rupture propagation at depth discarding the hypothesis of shaking-related gravitational collapse, although this cannot be excluded as a secondary effect enhancing at places the ruptures throws.

During the Norcia event, multiple faults belonging to the VBFS system ruptured at the surface, resulting in a large-scale complex deformation zone ranging between 70 and 3,000 $\mathrm{m}$ in width. Remote sensing surveys and a massive field reconnaissance led to a detailed mapping of the surface rupture (Civico et al., 2018; Villani, Civico, et al., 2018). Surface rupture occurs along closely spaced, parallel or subparallel, stepping (with overlap and underlap geometries) synthetic and antithetic fault splays pertaining to the VBFS and affects both bedrock and unconsolidated deposits. The broad deformation zone contains ground cracks and/or free faces, generally located at the base of preexisting fault scarps. Where the bedrock fault plane 


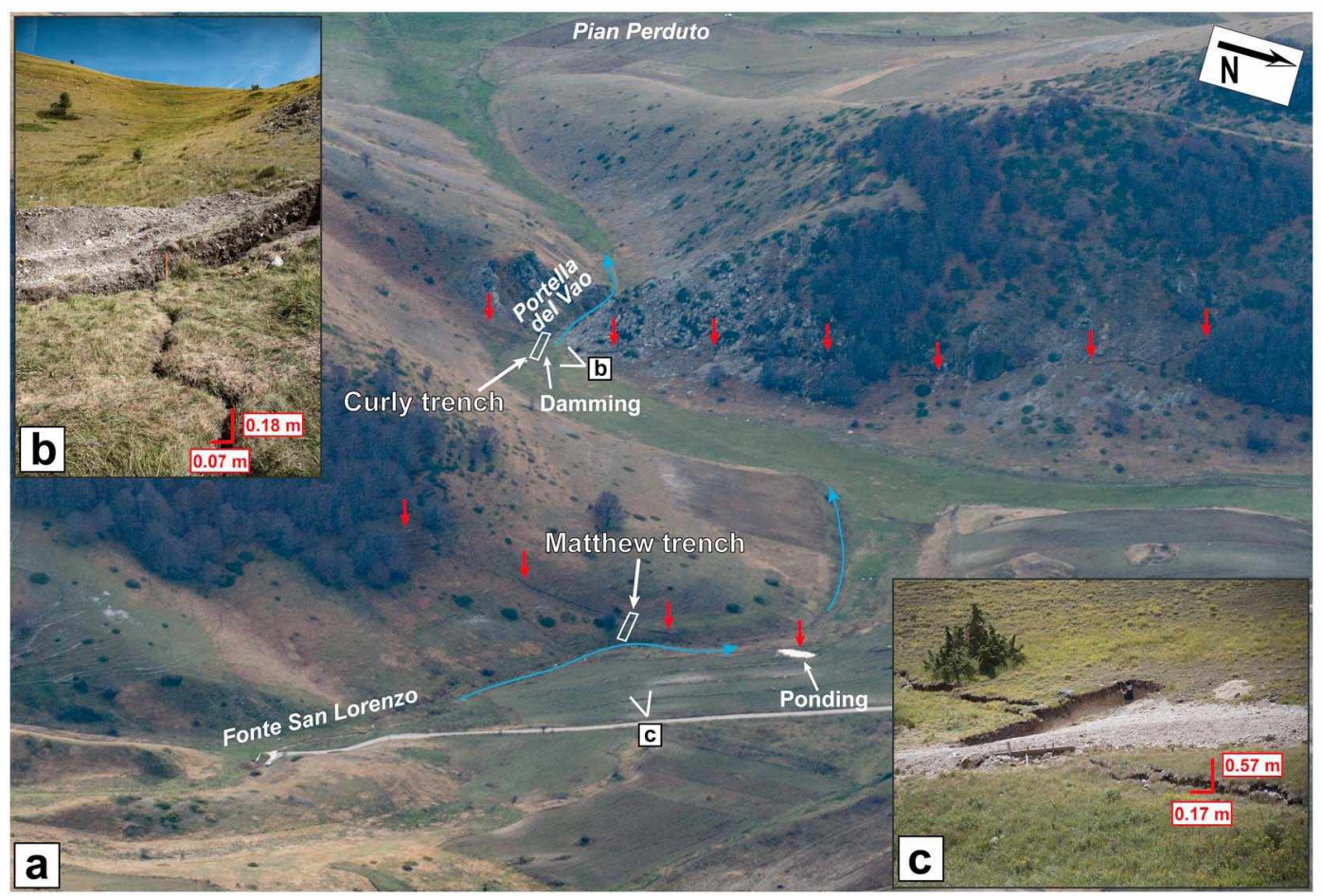

Figure 3. (a) Aerial view of the San Lorenzo site where the Curly and Matthew trenches are located (white rectangles indicate the excavations). Red arrows point to the antithetic earthquake rupture traces of the 30 October 2016 damming the streams (blue line). Location and view direction of photos in insets (b) and (c) are also indicated. View of the 2016 rupture and local values of the coseismic throw and opening (b) near the Curly trench and (c) near the Matthew trench.

is well preserved, the free face appears as a whitish, fresh ribbon at the base of the fault mirror, with fractures occurring in the scree/debris deposited on its hanging wall (Civico et al., 2018; EMERGEO Working Group, 2017a, 2017b; Figures 2 and 3).

The spatial and temporal development of the three main events of the sequence (Figures 1 and S1) offers a unique occasion to ponder on the meaning of surface faulting we may observe in trenches and on the uncertainties related to paleoseismological interpretations. During this sequence of mainshocks we were given the exceptional opportunity to observe and evaluate the coseismic geological effects of shocks occurring in the same crustal region, with different magnitudes.

The first observation of relevance for paleoseismology is that the 2016 sequence showed that ruptures can repeat along the same fault section (see also Schwartz, 2018) with only a few days/months delay. Trenching investigations cannot separate such discrete paleo-earthquakes so close in time and easily subject to overprinting by subsequent events. In fact, their combined slip could be interpreted as due to one single larger slip event, whereas in reality it is the cumulative effect of multiple events very close in time. A second consideration is that ruptures along the same fault section do not only show an increase of length with magnitude but also show an increase of their geometrical complexity. The deformation is distributed over multiple splays and hence is smaller and more difficult to recognize. The $2016 \mathrm{Mw} 6.5$ earthquake slip was partitioned along multiple ruptures, comprising a main and subsidiary antithetic and synthetic splays in a wide zone (Figures 1 and S2). These multiple ruptures allow for more potential trenching sites; however, paleoseismic investigation along one single rupture trace may be documenting only partial activity of the fault. This stresses further the importance of framing paleoseismological results within the broader setting of seismogenic structures (e.g., sections of high/low slip and multiple splays).

The knowledge acquired on the 2016 earthquake sequence is thus relevant for the paleoseismological analysis sensu lato and in particular can be used as a solid basis to test and improve our understanding of seismicity and of the seismic potential in the complex frame of the central Apennines using paleoseismology. 


\section{Trenching Along the Mw 6.5 Ruptures}

The 2016 surface faulting offers a unique opportunity to characterize the seismic behavior of the VBFS. In particular, the extensive ground ruptures formed during the Mw 6.5 Norcia event, highlighted more potential paleoseismological trenching sites, and increased the opportunities to recognize and characterize surface faulting events that occurred along the VBFS before 2016. The possibility to select trench sites also along secondary or antithetic scarps that ruptured a wide zone only during the Mw 6.5 Norcia earthquake was really critical because, although the ruptures on the main and known trace of the VBFS were clearly expressed at the surface over several kilometers, these run mainly along the western flank of VBFS at high elevations, with slip occurring in bedrock and scree deposits along steep slopes (often $>30^{\circ}$ ). Thus, the main trace of the 2016 ruptures was difficult to access and also useless for analysis of the stratigraphic/structural deformation and for recognition and dating of paleofaulting events, making the selection of suitable sites for trenching extremely limited.

Apart from this, the fact that the Norcia earthquake overprinted within a few months the ruptures from the two previous and smaller mainshocks (see also section 2) along the main trace of the fault also makes it more difficult to reconstruct the paleoseismological surface faulting record. Indeed, if this earthquake clustering (lasting days to several years) represents the typical behavior of the VBFS, then the correct identification of discrete single paleo-events may be biased by erosional/depositional processes and the subsequent overprinting of surface slip, leaving no stratigraphic evidence. This may lead to an overestimation of slip per event and recurrence times. For all of the above, we decided to investigate only the Mw 6.5 fault strands that ruptured exclusively on the 30 October Norcia earthquake and therefore to build a seismic history for Mw 6.5 Norcia type earthquakes.

We selected two sites: the San Lorenzo and the Forca di Presta sites located along the antithetic strand in the central portion of the rupture and along the synthetic strand at the southern tip of the rupture, respectively. The exact trench location was decided on the basis of the local geomorphology, the presence of long-term fault expression and of soft and recent sediments, and also the permissions obtained from the Sibillini Mountains National Park area, the local authorities and the land owners.

\subsection{The San Lorenzo Site}

The San Lorenzo site is located in the central sector of the 30 October 2016 earthquake rupture, where two antithetic, left-stepping rupture strands (Mt. Rotondo and San Lorenzo-Ghezzi; splays PRA1 and PRA2 in Villani, Pucci, et al., 2018; Figure 2a) extend for a total length of about $5 \mathrm{~km}$ from Colle Infante to the Ghezzi hut (Mt. Abuzzago; N320-345 striking, NE dipping). These are located at about $2.5 \mathrm{~km}$ of distance from the main synthetic trace running along the Mt. Porche and Mt. Argentella slopes, which presented coseismic maximum and average throws of $\sim 1.00$ and $0.25 \mathrm{~m}$, respectively, and an opening up to $0.35 \mathrm{~m}$ (Figures 1 and 2). The Mt. Rotondo antithetic rupture strand is $3.2 \mathrm{~km}$ long; it steps to the left with a 600$\mathrm{m}$-long overlap and 500-m-wide stepover to continue southward in the San Lorenzo-Ghezzi strand. The average coseismic throw due to the antithetic faults (splays PRA1 and PRA2) is $0.41 \mathrm{~m}$ (Villani, Pucci, et al., 2018). These ruptures follow a long-term cumulative fault scarp in both bedrock (Jurassic and Cretaceous limestone) and alluvium/colluvium (Pleistocene-Holocene; Figure 2a). The alluvium and colluvium deposits consist of fine to coarse calcareous gravels and sands and silty-clay layers from fluvial/alluvial deposition, and scree and talus deposits variably cemented. These soft sediments fill the graben formed between the synthetic and antithetic fault strands and form a small terraced plain. The NE facing antithetic coseismic free faces intercepted and dammed a SW flowing stream valley, thus forming a ponding area at the eastern rupture strand (PRA2; ponding in Figure 3). The western antithetic fault (PRA1) blocks the drainage at Portella del Vao, where the long-term incision across the footwall block created a narrow gorge flowing toward the Pian Perduto plain (Figure 3).

Two trenches were excavated at San Lorenzo site, one along each of the two antithetic fault strands in the overlapping zone (Figure 2a): the Curly trench to the west (lat $42^{\circ} 51^{\prime} 10.08^{\prime \prime} \mathrm{N}$, lon $13^{\circ} 12^{\prime} 43.87^{\prime \prime} \mathrm{E}$ ) and the Matthew trench to the east (lat $42^{\circ} 51^{\prime} 21.48^{\prime \prime} \mathrm{N}$, Lon $13^{\circ} 12^{\prime} 53.52^{\prime \prime} \mathrm{E}$ ). The initial location selected for the Curly trench was in the middle of the stream bed at Portella del Vao, but we were forced to move it a few meters to the south to avoid the messed-up area resulting from opening and closing of an excavation a few days before our planned work (trench T2 in Galli et al., 2019; see also Figure 1). The Matthew trench 
site was selected in the ponding area across the San Lorenzo stream bed; however, although potentially fruitful from a stratigraphic point of view, the site had a difficult logistic due to the shallow water table and the mandatory preservation of the natural stream bed, and thus, the Matthew trench was dug across a displaced remnant of a fluvial terrace on the left bank (Figure 3).

\subsubsection{The Curly Trench}

The trench intersects a $\sim 2.5$-m-wide, small, right-stepping zone of the 30 October 2016 antithetic rupture that runs in the hanging wall of the limestone fault plane (Figures $2 \mathrm{a}$ and 3), which is the evidence for the longterm activity of this fault splay. Unfortunately, the backhoe could not reach the limestone plane (located about $13 \mathrm{~m}$ upslope); there, the 2016 coseismic movement was highlighted by nearly 1 -cm-wide white ribbon and diffuse rock falls. The 2016 ruptures in the soft sediments crossed by the trench exhibit small vertical offsets of 0.04 to $0.10 \mathrm{~m}$, on the south and north walls, respectively, and a 0.2 -m-wide opening. These ruptures occurred on a preexisting gentle scarp located at the transition between the slope and the plain deposits, which is likely the cumulative expression of previous recent rupturing events (Figures 3a, 3b, and 4). The base of the scarp is modified by an artificial drainage channel built to conduct the slope wash toward the Portella del Vao gorge (Figure 4) and to avoid major flooding of the plain that threatens the plantations. Because of the strong modification, the cumulative scarp height is uncertain, ranging between 0.3 and $0.5 \mathrm{~m}$.

The stratigraphy exposed in the trench is composed of stratified fine to coarse slope-wash gravels (units $\mathrm{E}$ and B) interfingering with clayey silt of the alluvial plain (units $\mathrm{C}$ and $\mathrm{A}$ ). The radiocarbon dating of sample C150 (1920-1750 BCE; Table 1, calibrated ages are rounded to the nearest decade) from the base of unit A (bottom trench around meter 4 in the south wall; Figure 4) suggests that the whole stratigraphy exposed is younger than about 4 kyr. Below the cumulative scarp there is a $1-\mathrm{m}$-wide fault zone, composed of subvertical planes, F1 to F3 (N145-155 striking, NE dipping), that displace the whole sequence (meters $4-2$ in the north wall and 6-4 in the south wall; Figures 4 and S3). The fault zone separates the ponding fine rich sediments on the east from the coarser slope deposits. The 30 October 2016 earthquake ruptured the ground along fault plane F1 and produced some minor offset and cracking along F2 (Figure 4; most recent event, CE1 in both walls). Fault F1 displaces the whole stratigraphy below by the same amount; that is, it moved only once (in 2016) in the past about $4 \mathrm{kyr}$. The trench is located in a zone of slip transfer between adjacent rupture traces; therefore, we cannot exclude a geometric complexity at depth, with paired slip surfaces and rapid displacement variations along overlapping fault tips (e.g., Fossen \& Rotevatn, 2016). This may hamper straightforward recognition of the event horizons, particularly in the case of such minor amount of displacements in gravelly soils along single splays. This difficulty is even increased because unit D and the units below appear warped within the fault zone (F1 to F3). However, multiple evidence converges to set the occurrence of two events prior to 2016, namely, events CE2 and CE3. Evidence for both of them is provided by two discrete downward increases of vertical displacement with depth across the whole fault zone at, or near, the contact of unit $\mathrm{E} / \mathrm{D}$ and at, or near the top, of unit A, respectively (0.04-0.10 to $0.22-0.25 \mathrm{~m}$ and $0.22-0.25$ to $0.30-0.36$ $\mathrm{m}$; Figure $\mathrm{S} 4$ and Table 2). The individual throw for CE2 would be in the range $0.12-0.21 \mathrm{~m}$, whereas for CE3 it is $0.05-0.14 \mathrm{~m}$. Further evidence for CE2 is given by (1) the upward fault termination of F3 on both walls and (2) the presence of unit $E$ on both walls, which is composed of medium and large limestone blocks, particularly concentrated on the steepest part of the slope (meters 8 to 11, Figure 4; see also Figure S3). On the basis of what was observed in 2016, these blocks are interpreted as a coseismic rock fall related to the shaking of the penultimate event. A similar interpretation can be attributed to the slope-derived coarsegravel unit B in the fault zone, evidencing the occurrence of CE3. A further indication for CE2 is the trace of F2 crossing the lower portion of unit D on the north wall, although we could not clearly trace its upward termination (Figure S3).

Constraints on the age of the penultimate event (CE2) are provided by radiocarbon dates from charcoal sample C7 (590-670 CE) and bulk sediment sample C23 (260-430 CE) from unit D and from bulk sediment sample C24 (1220-1290 CE) of unit F immediately on top of unit E (Table 1 and Figures 4 and S5). Samples C7 and C23 were collected in the two different walls, and given the differences between the two walls, we had difficulties to define their relative stratigraphic position. Assuming they are both in unit D, to overcome this problem and be conservative, we take as representative of unit $\mathrm{D}$ the whole age interval given by the two sample ages, that is, 260-670 CE. Therefore, the age range of CE2 from this trench is quite wide between 260 and $1290 \mathrm{CE}$. The age of the third event, CE3, would be older than the age of C7/C23 (260-670 CE) and younger than that of $\mathrm{C} 150(1920-1750 \mathrm{BCE})$, thus in the range $1920 \mathrm{BCE}$ to $670 \mathrm{CE}$. 

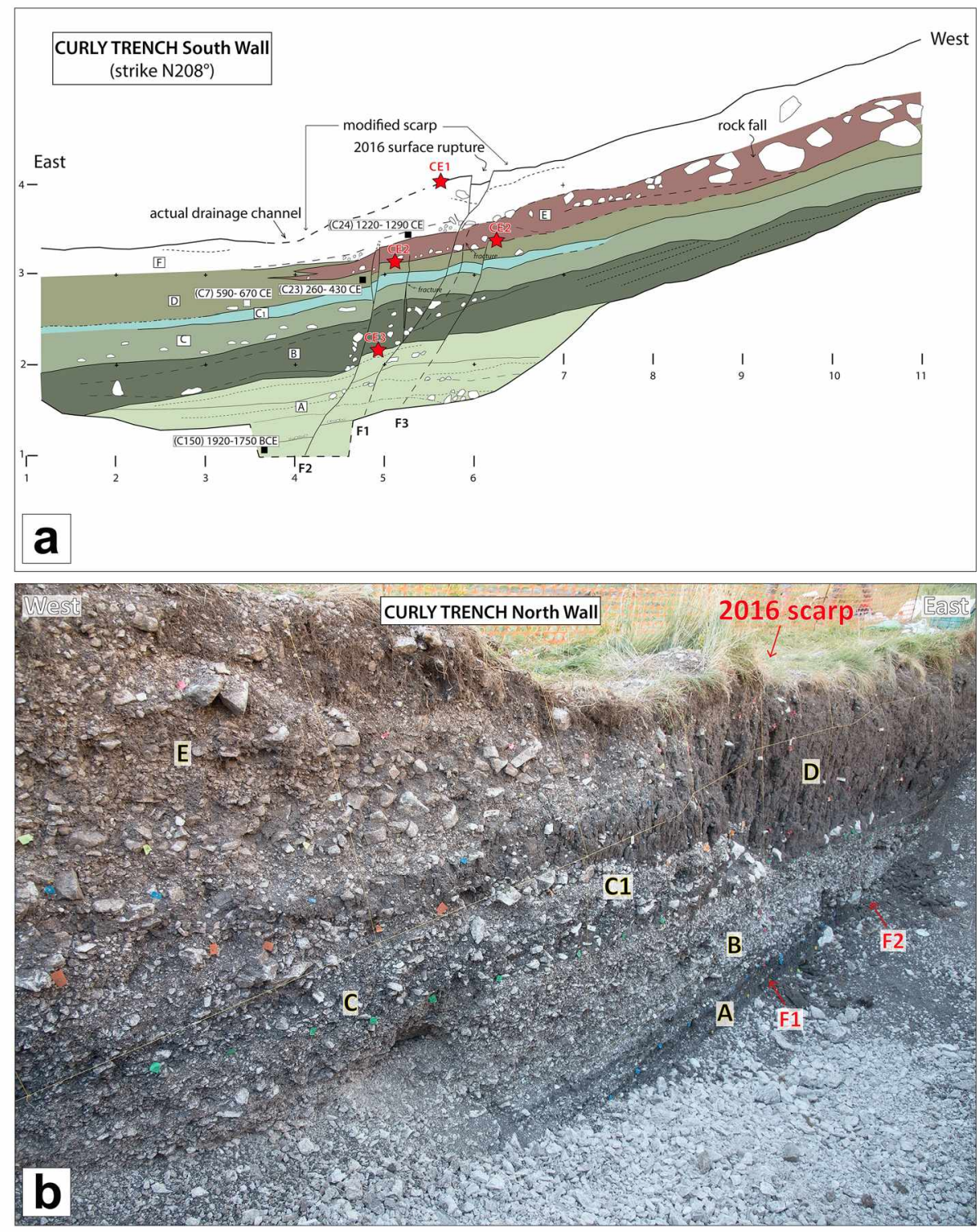

Figure 4. (a) Simplified log of the south wall of the Curly trench from a 1:20-scale survey. Grid spacing is $1 \mathrm{~m}$. Black squares indicate dated radiocarbon samples, white colored when projected from the north wall (Table 1). Red stars indicate location of event horizons (ground surfaces at the time of surface faulting earthquakes). Faults are indicated with progressive numbers, F1 to F3. Events are referred to as CE1 to CE3, starting from 30 October 2016. (b) View of the north wall. Different letters refer to stratigraphic units. Legend: unit $\mathbf{F}=$ very loose, thin gravelly layer, clast supported (size max $5 \mathrm{~cm}$ ) and pedogenized on top; unit $\mathrm{E}=$ rocky gravel including clasts with max size of $15 \mathrm{~cm}$, matrix supported between meters 4 and 6 , and large boulders up to $50 \mathrm{~cm}$ between meters 7 and 11 (rock fall); unit $\mathrm{D}=$ brown matrix-supported clayey silt, richer in clasts toward the slope, interfingering with slope deposit of unit $\mathrm{E}$; unit $\mathrm{Cl}=$ gravel horizon within the massive clayey silt of unit $\mathrm{C}$, becoming much thinner in the hanging wall fault zone (meters $4-3$ north wall); unit $\mathrm{C}=$ dark brown massive clayey silt with sparse, fine to coarse pebbles (ponding phase), abundant toward the slope, darker below unit $\mathrm{Cl}$, with the base marked by very coarse flat pebbles and cobbles (size max $15 \mathrm{~cm}$ ); unit B = stratified coarse gravel with skewed pebbles poor in matrix content, richer in matrix, and of larger-sized clasts in the middle portion, smaller clasts and yellowish matrix increase in the footwall; unit A =massive dark brown clayey silt (ponding phase) with intercalation of coarse gravelly horizons, increasing thickness and pebble size toward the slope.

\subsubsection{The Matthew Trench}

The trench was dug on a fluvial terrace crossed by the 2016 antithetic east facing, right-stepping, coseismic rupture trace running almost parallel to the slope direction at the base of a smoothed scarp that represents the long-term expression of the fault activity (Figures 3a and 3c). The total vertical throw across the 2016 
Table 1

${ }^{14} \mathrm{C}$ Dated Samples From the Trenches With Conventional and Calibrated Ages

\begin{tabular}{|c|c|c|c|c|c|c|c|c|}
\hline $\begin{array}{l}\text { Trench- sample } \\
\text { code }\end{array}$ & $\begin{array}{c}\text { Sample position } \\
\text { (wall/hor meter/vert meter) }\end{array}$ & $\begin{array}{l}\text { Trench- } \\
\text { unit }\end{array}$ & Lab code & $\begin{array}{l}\text { Sample } \\
\text { type }\end{array}$ & $\begin{array}{c}\delta^{13} \mathrm{C} \\
\text { (IRMS) }\end{array}$ & $\begin{array}{l}\text { Conventional age } \\
\text { (before } 1950=\mathrm{BP} \text { ) }\end{array}$ & $\begin{array}{l}\text { Calibrated age } \\
(2 \sigma)\end{array}$ & $\begin{array}{l}\text { Probability } \\
\text { distribution }\end{array}$ \\
\hline $\begin{array}{l}\text { Matthew- } \\
\text { MATT\#12 }\end{array}$ & $\mathrm{SW} / 4-5 / 2-3$ & TM-D & Beta-471116 & Bulk & -24.2 & $1540 \pm 30 \mathrm{BP}$ & $430-590 \mathrm{CE}$ & 1.000 \\
\hline $\begin{array}{l}\text { Matthew- } \\
\text { MATT\#5 }\end{array}$ & $\mathrm{SW} / 2-3 / 1-0$ & TM-A & Beta-471117 & Bulk & -23.0 & $3520 \pm 30 \mathrm{BP}$ & 1930-1750 BCE & 1.000 \\
\hline $\begin{array}{l}\text { Matthew- } \\
\text { MATTH1 }\end{array}$ & $\mathrm{NW} / 2-3 / 1-2$ & TM-B & Beta-475297 & Bulk & -23.9 & $2120 \pm 30 \mathrm{BP}$ & $\begin{array}{l}\text { 340-320 BCE } \\
210-50 \mathrm{BCE}\end{array}$ & $\begin{array}{l}0.040 \\
0.960\end{array}$ \\
\hline $\begin{array}{l}\text { Matthew- } \\
\text { MATTH4 }\end{array}$ & $\mathrm{SW} / 2-3 / 1-2$ & TM-E & Beta-475296 & Bulk & -24.4 & $1260 \pm 30 \mathrm{BP}$ & $\begin{array}{l}670-780 \mathrm{CE} \\
790-830 \mathrm{CE} \\
840-860 \mathrm{CE}\end{array}$ & $\begin{array}{l}0.899 \\
0.058 \\
0.043\end{array}$ \\
\hline Curly-C23 & SW/4-5/2-3 & TC-D & Beta-475295 & Bulk & -24.6 & $1670 \pm 30 \mathrm{BP}$ & $\begin{array}{l}260-280 \mathrm{CE} \\
320-430 \mathrm{CE}\end{array}$ & $\begin{array}{l}0.061 \\
0.939\end{array}$ \\
\hline Curly-C24 & SW/5-6/3-4 & TC-F & Beta-471115 & Bulk & -24.7 & $740 \pm 30 \mathrm{BP}$ & $1220-1290 \mathrm{CE}$ & 1.000 \\
\hline Curly-C150 & $\mathrm{SW} / 3-4 / 1-2$ & TC-A & Beta-471114 & Bulk & -24.4 & $3510 \pm 30 \mathrm{BP}$ & 1920-1750 BCE & 1.000 \\
\hline Curly-C7 & $N W / 1-2 / 2-3$ & TC-D & Poz-95416 & Charcoal & np & $1410 \pm 30 \mathrm{BP}$ & 590-670 CE & 1.000 \\
\hline Hope-C202 & $\mathrm{SW} / 6-7 / 2-3$ & TH-D & Beta- 475298 & Bulk & -23.6 & $6940 \pm 30 \mathrm{BP}$ & $5890-5740$ ВСЕ & 1.000 \\
\hline Hope-C204 & $\mathrm{SW} / 10-11 / 1-2$ & TH-Cw & Beta-475299 & Bulk & -23.6 & $15330 \pm 40 \mathrm{BP}$ & $16780-16540 \mathrm{BCE}$ & 1.000 \\
\hline Hope-C205 & $\mathrm{SW} / 13-14 / 0-1$ & TH-F & Poz-95770 & Bulk & $\mathrm{np}$ & $17650 \pm 140 \mathrm{BP}$ & $19820-18990 \mathrm{BCE}$ & 1.000 \\
\hline Hope-E1 & $\mathrm{SW} / 13-14 / 1-2$ & TH-A & Beta-471119 & Bulk & -24.7 & $4520 \pm 30 \mathrm{BP}$ & $\begin{array}{l}3360-3260 \mathrm{BCE} \\
3240-3100 \mathrm{BCE}\end{array}$ & $\begin{array}{l}0.337 \\
0.663\end{array}$ \\
\hline Hope-E3 & $\mathrm{SW} / 13-14 / 1-2$ & TD & Poz-95772 & Bulk & np & $10360 \pm 90 \mathrm{BP}$ & $\begin{array}{l}\text { 10590-9990 BCE } \\
9930-9890 \mathrm{BCE}\end{array}$ & $\begin{array}{l}0.976 \\
0.024\end{array}$ \\
\hline
\end{tabular}

Note. Measured radiocarbon ages were corrected for isotopic fractionation, calculated using the $\delta^{13} \mathrm{C}$ (except when np $=$ not provided by the Lab). Calibrated ages were obtained by correction for the ${ }^{12} \mathrm{C} /{ }^{14} \mathrm{C}$ changes in the atmosphere using OxCal 4.3 (Bronk Ramsey, 2009) with the IntCal 13 atmospheric curve (Reimer et al., 2013) and were rounded to the nearest decade. The chronological distribution of the radiocarbon ages is available in Figure S5. SW $=$ south wall; NW $=$ north wall. Trench: TM = Matthew; TC = Curly; TH = Hope. Lab code: Beta $=$ Beta Analytic Radiocarbon Dating Laboratory $($ Florida, USA); Poz $=$ Poznan Radiocarbon Laboratory (Poland).

main and secondary scarps on the south wall is $0.42-0.49 \mathrm{~m}$ with an opening at the main rupture of $0.40 \mathrm{~m}$ (Faults F1 and F2; Figure 5a). On the north wall, the 2016 rupture is expressed as a 0.10 -m-wide open fissure with no appreciable net vertical offset; this evident decrease in the amount of surface slip is due to the trench location in a relay zone of the rupture (Figure $3 \mathrm{c}$ ).

In the following, we will discuss stratigraphic and structural relations of the south wall because there the evidence of multiple past surface ruptures was clearer. The stratigraphic sequence is mainly composed of gravels with different amounts and types of matrix, both of slope and alluvial origin. The radiocarbon dating on sample Matt\#5 (1930-1750 BCE) from the base of unit A (Figure 5) indicates that the whole stratigraphy is younger than about $4 \mathrm{kyr}$, similar to the Curly trench (see section 3.1.1).

Across the 2016 main rupture, all the units are sheared and displaced within a 0.9 -m-wide fault zone (F1; Figure 5). This is composed of near-vertical fault splays joining in a single plane at about $1.5-\mathrm{m}$ depth

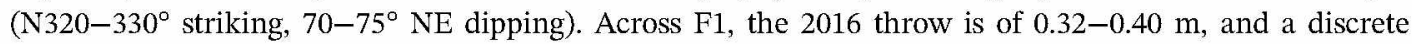
increase of the amount of throw with depth is observed at the erosional contact between unit D and unit $\mathrm{C}$ (Figures S4 and S6). In fact, removing the 2016 throw, this contact still defines a 0.16- to 0.28-m-high paleoscarp draped by unit D across F1. This suggests that a penultimate surface faulting event (ME2) occurred at or near this contact in the stratigraphy (Figure 5a). The deposit marked as unit $\mathrm{Cw}$ is a distinct wedge-shaped deposit of pebbly loose colluvium with internal bedding, burying a free face and likely derived from the dismantling of unit C. It is confined in the hanging wall of fault F1 and successively faulted. This unit is interpreted as the scarp-derived colluvial wedge following the penultimate event of surface faulting at fault plane F1 (Figure S6). Evidence for the ME2 event is found also at Fault F2 (meter 4.5), which clearly ruptures units $\mathrm{C}^{\prime}$ and $\mathrm{C}$, forming a small graben structure filled with large clasts. It is worth noting that we never base the recognition of event horizons only on stratigraphic evidence (e.g., colluvial wedges) but on multiple signatures. The total vertical displacement across F2 of units $\mathrm{C}^{-\mathrm{C}^{\prime}}$ amounts to $0.23-0.28 \mathrm{~m}$. Subtracting from this cumulative value that produced by the 2016 rupture at the surface $(0.09-0.10 \mathrm{~m})$, yields a ME2 coseismic vertical displacement of $0.13-0.19 \mathrm{~m}$ at F2 (Figure S4). Additional evidence for the occurrence of ME2 before the 
Table 2

Throw per Event: Values Measured in Each Trench and Total Throw per Event Derived for Single Fault Splay

\begin{tabular}{|c|c|c|c|c|}
\hline \multicolumn{5}{|l|}{ Throw per Event } \\
\hline Trench event code & Throw across the fault zone $\mathrm{e}^{\mathrm{a}}(\mathrm{m})$ & Average Throw with standard deviation ${ }^{\mathrm{c}}(\mathrm{m})$ & Correlated event & Total Throw per event ${ }^{\mathrm{d}}(\mathrm{m})$ \\
\hline CE1 (2016) & $0.04-0.10$ & $0.07 \pm 0.02$ & E1 (Antithetic) & $0.52 \pm 0.03$ \\
\hline$C E 2$ & $0.12-0.21$ & $0.17 \pm 0.03$ & E2 (Antithetic) & $0.65 \pm 0.06$ \\
\hline CE3 & $0.05-0.14$ & $0.10 \pm 0.03$ & E3 (Antithetic) & $0.20 \pm 0.04^{\mathrm{b}}$ \\
\hline ME1 (2016) & $0.42-0.49$ & $0.45 \pm 0.02$ & E4 (Synthetic) & $0.55 \pm 0.07$ \\
\hline$M E 2$ & $0.46-0.49$ & $0.48 \pm 0.05$ & E5 (Synthetic) & $0.30 \pm 0.06$ \\
\hline$M E 3$ & $0.05-0.14^{\mathrm{b}}$ & $0.10 \pm 0.03$ & E6 (Svnthetic) & $0.48+0.01$ \\
\hline HEI & $0.45-0.65$ & $0.55 \pm 0.07$ & E7 (Synthetic) & $0.35 \pm 0.03^{b}$ \\
\hline HE2 & $0.20-0.40$ & $0.30 \pm 0.06$ & & \\
\hline HE3 & $0.45-0.50$ & $0.48 \pm 0.01$ & & \\
\hline HE4 & $0.30-0.40$ & $0.35 \pm 0.03^{b}$ & & \\
\hline
\end{tabular}

${ }^{a}$ Minimum and maximum values calculated across the whole fault zone in the trench (Curly) or adding throws on single splays (Matthew and Hope). ${ }^{b}$ Minimum values. ${ }^{c}$ Standard deviation computed by assuming a uniform probability distribution for the throw values. ${ }^{\mathrm{d}}$ Total throw per event derived for single fault splay.

deposition of unit $\mathrm{D}$ is found at meter 1.3 , where fault $\mathrm{F} 3$ crosses and displaces unit $\mathrm{B}$ by $0.08-0.11 \mathrm{~m}$ and does not propagate upward within the sequence (Figure 5). Summing the throws related to ME2 individually measured at F1 $(0.16-0.28 \mathrm{~m}), \mathrm{F} 2(0.13-0.19 \mathrm{~m})$, and F3 $(0.08-0.11 \mathrm{~m})$, an aggregate throw up to $0.46-0.49$ $\mathrm{m}$ is obtained for this event (Table 2). Evidence for a third event, ME3, is found within unit B at meter 4.1; here fault F4 acts as antithetical to F2 and puts in contact unit A with unit B, with an indeterminable amount of displacement. This fault splay was possibly reactivated during the event ME2 (Figures 5 and S6).

ME2 event horizon is located between samples MATT\#1 and MATT\#12; thus, it occurred in an age range 50 BCE to 590 CE (Figure S5). However, the relative position of ME2 (base of unit D) with respect to dated sample MATT\#12 (Table 1 and Figure 5a) would set the timing of ME2 closer to 430-590 CE. Constraints on the age of ME3 are provided by radiocarbon ages on bulk sediment sample MATT\#1 (340-50 BCE) from unit B and MATT\#5 (1930-1750 BCE) from unit A (Table 1 and Figure S5). Although with large uncertainties, ME3 occurred between 1930 and $50 \mathrm{BCE}$.

\subsection{The Forca di Presta Site}

The Forca di Presta site is located at the southernmost sector of the 30 October 2016 earthquake rupture, where a synthetic rupture strand (coded as VET6 in Villani, Pucci, et al., 2018; Figures 2b and 6) extends for about $1.9 \mathrm{~km}$ with a $\sim \mathrm{N}-\mathrm{S}$ strike and downthrows to the west (for details see the coseismic rupture map in Civico et al., 2018). The 2016 coseismic ruptures along this strand are characterized by an average throw of $0.07 \mathrm{~m}$ and a maximum throw of $0.31 \mathrm{~m}$ (Villani, Civico, et al., 2018,Villani, Pucci, et al., 2018) with the values decreasing southward, always with a dominant normal component. Even considering the contribution of the parallel easternmost rupture splay (VET7 in Villani, Pucci, et al., 2018), the average net throw of the southernmost sector of the VBFS does not exceed $0.08 \mathrm{~m}$. The 2016 ruptures mostly follow a cumulative fault scarp (average scarp height of $3.2 \mathrm{~m}$; see also section 4.3) in both bedrock (Cretaceous limestone) and alluvium/colluvium (Pleistocene-Holocene). Here the earthquake rupture and the long-term cumulative scarp (always west-side down) run along the eastern flank of the Mt. Forciglieta ridge and, because of their downthrows to the west, produce an antislope scarp forming a double-crested ridge. This creates, over most of the scarp length, a local ridge-top depression where alluvial/colluvial deposits are trapped, due to the damming of small east flowing drainages. The formation of dolines within the depression is common due to the limestone bedrock (Figures $2 \mathrm{~b}$ and 6 ).

A good location for trenching purposes in terms of soft and recent sediments is a 30- to 40-m-wide, small valley, dammed by two west facing subtle subparallel, long-term morphologic scarps, about 5-7 $\mathrm{m}$ apart and $\sim 0.3 \mathrm{~m}$ high (Figure 6 ). The 2016 ruptures do not appear to intersect this valley at the surface but may be concealed by the occurrence of a doline located at the base of the scarps, where the coseismic rupture can be projected. Therefore, to determine the best location for a trench, we have performed an electrical 


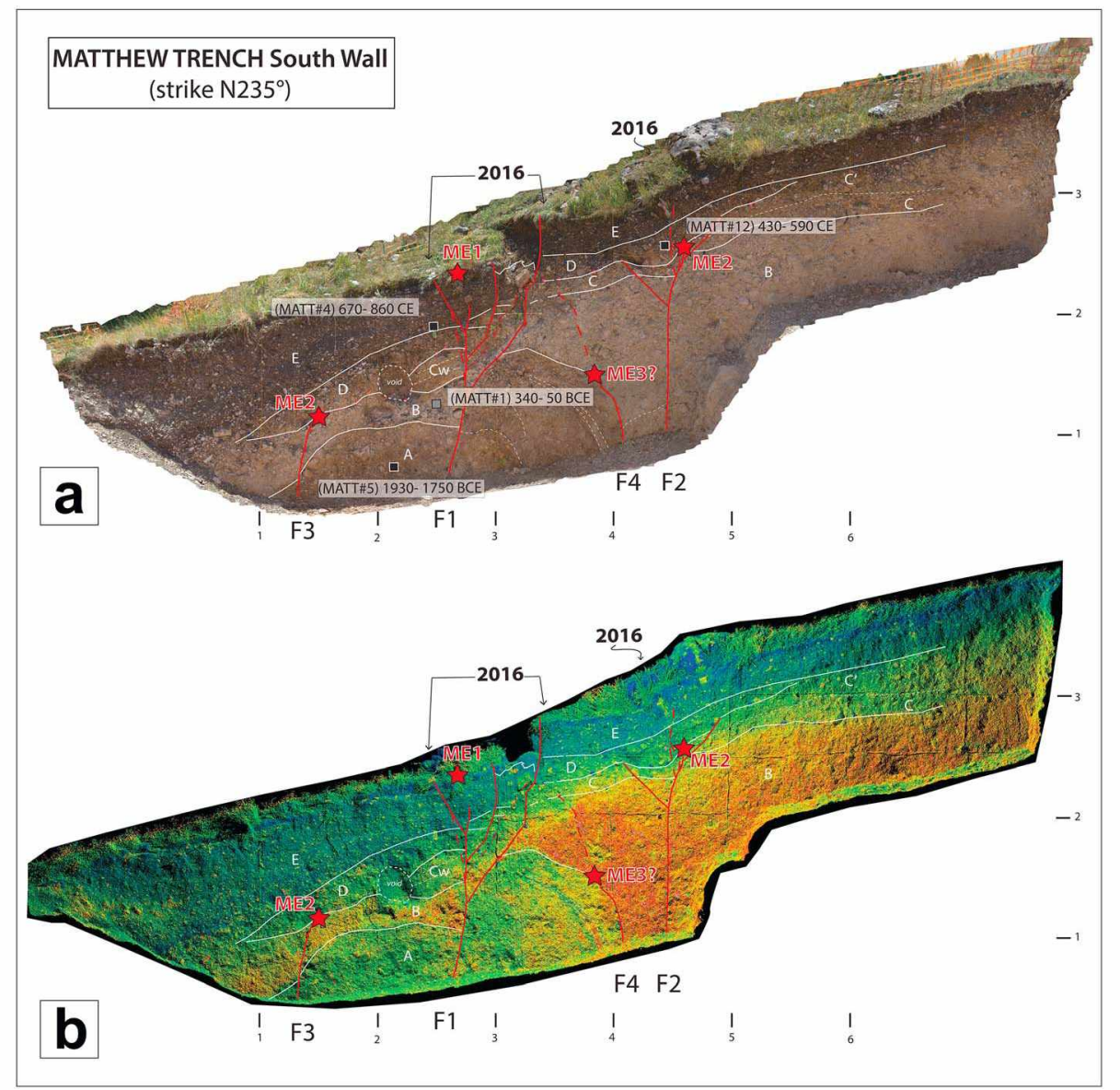

Figure 5. View and interpretation of the south wall of the Matthew trench. (a) Orthophotomosaic with simplified line drawing of the stratigraphic and structural setting from the 1:20-scale survey. Grid spacing is $1 \mathrm{~m}$. Black squares indicate dated radiocarbon samples, white squares indicate sample projected from the north wall (all bulk type; Table 1). Mosaic is generated by structure-from-motion photogrammetry from ground-based imagery. (b) Terrestrial laser scanning point cloud of the south wall (data at https://doi.org/10.5069/G9G15Z03). The variety of colors indicates different reflectance of the materials hit by the laser. Note how this parameter highlights the different deposits and the structures, in agreement with the field survey (simplified log superimposed). Red stars indicate location of event horizons (ground surfaces at the time of surface faulting earthquakes). Stratigraphic units are: unit $\mathrm{A}=$ reddish to brownish massive, oxidized, and matrix supported gravel; unit $\mathrm{B}=$ gravel with whitish carbonate matrix and coated pebbles; unit $\mathrm{C}=$ heterogeneous, rounded, fine pebbles with a scarce content of hazel to brownish silty matrix weathered at the base (fluvial terrace); unit $\mathrm{C}^{\prime}=$ pedogenized unit $\mathrm{C}$; unit $\mathrm{Cw}=$ colluvial deposit made of medium to fine loose pebbles, scarce oxidized matrix, with internal bedding likely derived from the dismantling of unit $\mathrm{C}$; unit $\mathrm{D}=$ gravel with angular pebbles in poor matrix; unit $\mathrm{E}=$ pebbly organic coating soil.

resistivity tomography profile, about $90 \mathrm{~m}$ long, acquired with a capacitive-coupled resistivity meter (OhmMapper system powered by Geometrics(); Figure 6c). To gather the highest near-surface resolution, apparent resistivity was measured using a multireceiver array with a $5-\mathrm{m}$ dipole-dipole transmitter and receiver cables with a potential investigation depth of the order of $10 \mathrm{~m}$. A current is applied from the transmitter to the ground via capacitive coupling, and the measured voltage at the receivers is a function of the subsurface electrical property (i.e., ground resistivity) between the transmitter current and the receiver dipoles (Kuras et al., 2006). Raw data have been filtered and despiked to remove clear outliers and then inverted using a least squares inversion with smoothness constraints to recover the 2-D resistivity distribution at depth (Loke \& Barker, 1996). The resistivity section shows the presence in the uppermost $\sim 4 \mathrm{~m}$ of a moderately resistive layer (up to $\sim 100 \Omega \cdot \mathrm{m}$ ) thickening to the west and on top of a more resistive layer $(>300 \Omega \cdot \mathrm{m}$ ). We interpreted the upper layer as colluvium and fine slope debris and the bottom layer as the weathered marly limestone bedrock (Figure 2) that is outcropping at the eastern edge of the section (see also section 4.3). The resistive layer at the bottom clearly shows two small inflections (white arrows in Figure 6c). These buried inflections are consistent with the position of two 


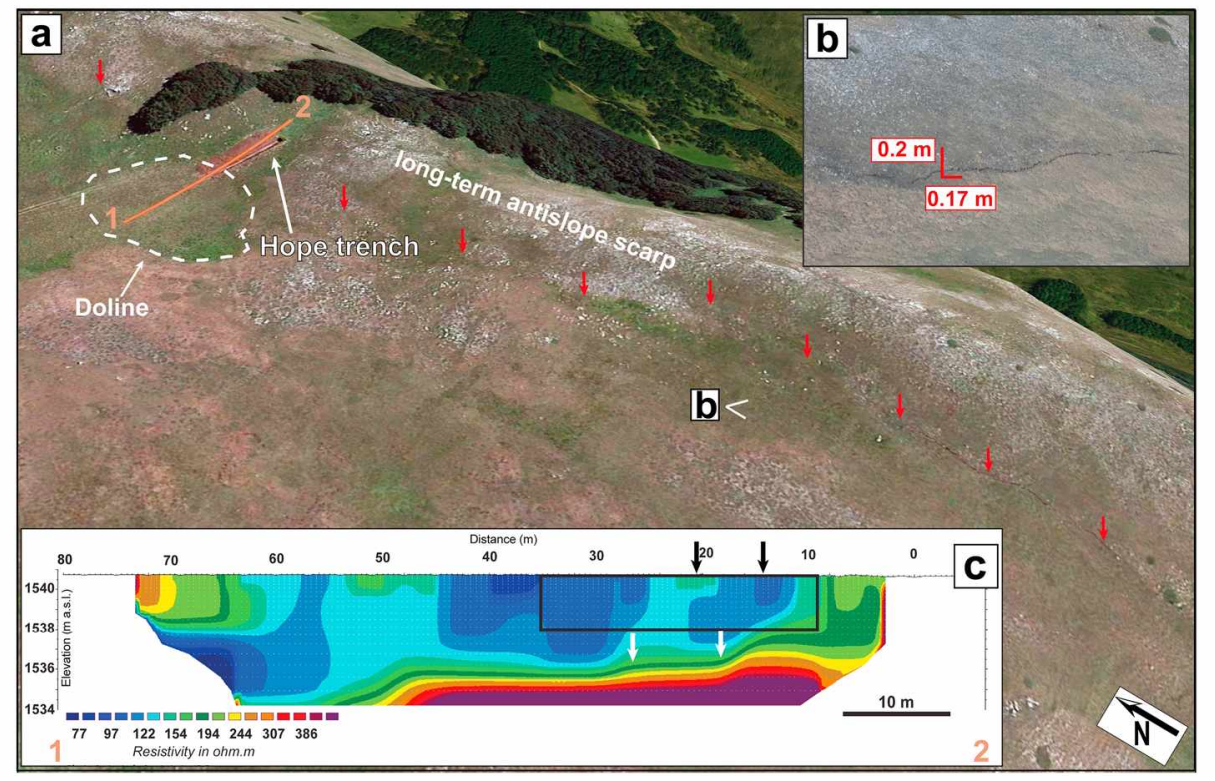

Figure 6. (a) Aerial view of the Forca di Presta site where the Hope trench is located (white arrow). Red arrows point to the synthetic earthquake rupture trace of 30 October 2016 that bounds the ridge-top depression for most of its length. Orange line 1-2 is the trace of the electrical resistivity profile shown in inset (c). (b) View of the 2016 coseismic rupture and local values of the throw and opening (for location and view direction see panel a). (c) About 90-m-long electrical resistivity profile acquired with a capacitive-coupled resistivity meter (orange trace 1-2 in panel a). Root mean square error $3.8 \%$ after seven iterations. White arrows in the resistivity profile point to the small inflections at the top of the weathered marly limestone bedrock (more resistive layer) and are consistent with the position of the topographic antislope long-term inflections (black arrows; see also section 4.3 and Figure 7). The black rectangle indicates the trench location.

minor scarps at the surface (black arrows in Figure 6c) related to west dipping faults. These results confirm the tectonic origin of the antislope scarp and the suitability of the site for digging the Hope trench (Figure $2 \mathrm{~b}$; lat $42^{\circ} 47^{\prime} 1.45^{\prime \prime} \mathrm{N}$, lon $13^{\circ} 15^{\prime} 40.56^{\prime \prime} \mathrm{E}$ ).

\subsubsection{The Hope Trench}

In the following we will discuss only the south wall of the Hope trench because there units and relative stratigraphic and structural relations clearly highlight multiple past coseismic surface ruptures across three fault zones (F1, F2, and F3; Figure 7).

The outcropping bedrock to the east of the trench is exposed in the lower part of the wall as highly weathered marly limestone (unit G) made of fractured blocks. Unit $\mathrm{G}$ is buried by colluvium and fine slope deposits mainly represented by hazel to brown silt with sparse pebbles and by small pebbly-gravel lenses with scarce lateral continuity (Figure 7). In general, the older stratigraphy in the eastern portion of the wall is quite massive; therefore, units $\mathrm{F}$ and $\mathrm{E}$ are difficult to be distinguished.

A description of the stratigraphy is reported in the caption of Figure 7. Radiocarbon dating on sample E1 (3360-3100 BCE, Table 1) and sample C205 (19820-18990 BCE, Table 1), respectively collected at the top (unit A) and base (unit F) of the trench, indicates that the whole stratigraphy exposed on the trench walls is older than $5 \mathrm{kyr}$ and younger than about $22 \mathrm{kyr}$. The lack of younger deposits is likely due to the erosional and karst processes affecting the site and/or to the westward migration of the tectonic scarp in recent times and consequent erosion of the eastern sectors (Figure 6; see also section 3.2). In this latter case, the tectonic trap for recent sediments in the hanging wall of the fault zone would have moved a few meters to the west where digging was not allowed because of National Park rules.

The eastern fault zone (F1; meters 5-7 in Figure 7a) is made of five splays named F1a to F1e and coincides with the easternmost topographic antislope inflection highlighted by the geophysical survey at depth (right black arrow in Figure 6c).

Fault splays F1a, F1b, and F1c appear to cut the entire sequence up to unit B. We were not able to confidently trace these faults through the active soil (unit A) at any place along this trench, but we cannot exclude that some minor shearing occurred in this unit too and possibly during the 2016 earthquake (as, 


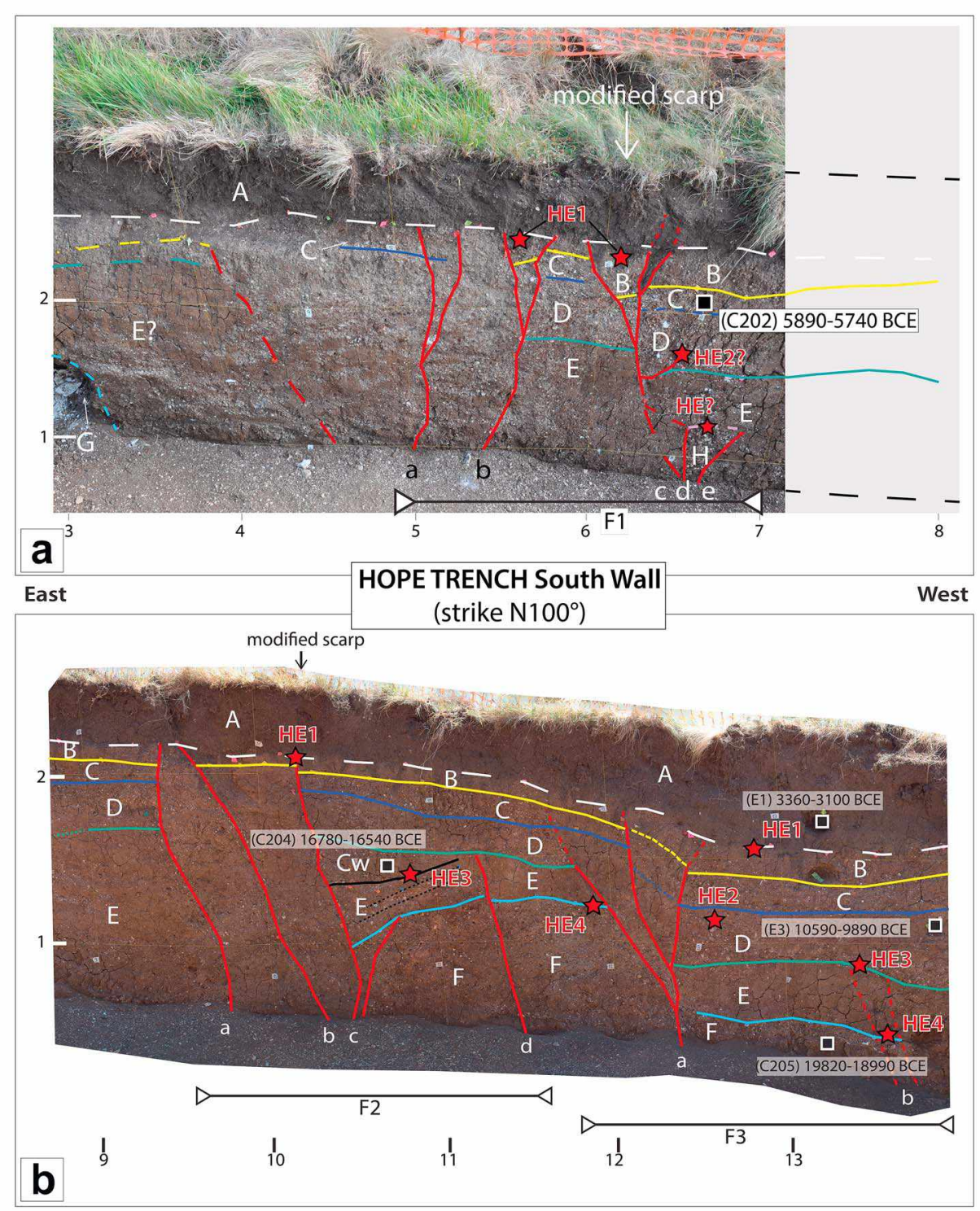

Figure 7. Simplified logs of the fault zones on the south wall of the Hope trench from a 1:20-scale survey superimposed on (a) photo (meters 7-8, not covered by the image, top and bottom of the trench marked by dashed black lines) and (b) orthophotomosaic generated by structure-from-motion photogrammetry from ground-based imagery. Grid spacing is $1 \mathrm{~m}$. Black squares indicate dated radiocarbon samples and relative age (Table 1). White capital letters refer to the stratigraphic units described in the legend below. Limits of the units are identified with colored lines. Faults are traced with red lines, dashed when inferred, and fault zones are indicated with progressive numbers, F1 to F3, and letters indicate the individual splays. Red stars locate the event horizons (ground surfaces at the time of surface faulting earthquakes). Events are referred to as HE1 to HE4, starting from the most recent event. Question marks are used when the event horizon position is uncertain. Legend: unit $\mathrm{A}=$ active soil unit, about $30-40 \mathrm{~cm}$ thick, composed of an active topmost layer (15 to $20 \mathrm{~cm}$ thick) and a B-soil horizon below; unit B = hazel to yellowish silt, about 10-15 cm thick, with very fine to fine sparse pebbles; unit $\mathrm{C}=$ fine gravel in a poor silty matrix, $10-20 \mathrm{~cm}$ thick; unit $\mathrm{D}=$ brown silt within a clear continuous fine gravel layer at the bottom; unit $\mathbf{E}=$ brown silt, darker at the bottom, with sparse pebbles and several thin (3-5 $\mathrm{cm}$ thick) pebbly-gravelly lenses with no lateral continuity in the uppermost $0.5 \mathrm{~m}$; unit $\mathrm{F}=$ brown to dark brown silt with a peculiar $10-20 \mathrm{~cm}$ thick gravelly layer at the top; unit $\mathrm{G}=$ weathered marly bedrock made of fractured limestone blocks within a brown silty matrix; unit $\mathrm{H}=$ angular to subangular carbonatic pebbles in a poor silty matrix; $\mathrm{Cw}=$ colluvial wedge, made of alternating fine clast-supported and brown silty layers, with internal bedding.

for example, along the splay F1c). The main offset occurs on F1c and is about $0.20 \mathrm{~m}$. Unit B shows $0.10-0.15 \mathrm{~m}$ of thickening in the F1c hanging wall probably related to postevent scarp degradation. The top of unit B can be considered as the event horizon for the most recent (excluding minor cracks in 
unit A) surface faulting event recognized at F1 (HE1). Along F1c, at about 1-m depth, a small splay branches from the main trace in the hanging wall within unit $D$, similarly to that involving unit $B$ and unit $C$ above. This may be evidence for a previous faulting event (HE2?). At meter 6.5, an about 0.2-m-wide, V-shaped structure is bounded by F1d and F1e. This is infilled by coarse gravel (unit $\mathrm{H}$ ) probably derived from the local bedrock, a few meters eastward, and capped by unit $\mathrm{E}$. Thus, the top of unit $\mathrm{H}$ can be interpreted as the stratigraphic level where a further earthquake (HE?) occurred. Uncertainty affects the position of this event horizon and its possible correlation with other events recognized within the trench wall.

The second fault zone (F2) consists of four fault strands F2a to F2d (meters 9-11.5 in Figure 7b). A gentle 0.2m-high morphologic scarp appears at the surface in alignment with the center of this fault zone and coincides with the westernmost topographic antislope inflection. F2 is also aligned with the inflection depicted at depth in Figure 6c. Fault splays F2a and F2b define an about 0.4-m-wide zone in a highly sheared, chaotic brown silt with no clear stratigraphy. The shear zone cuts up to unit B, even though with almost no vertical offset. Also, F2c affects the deposits up to unit B with a vertical offset of about $0.05 \mathrm{~m}$. As in F1 we cannot exclude minor shearing in unit A, then the top of unit B can be set as the most recent event horizon (HE1). Offset measurement on the older units across F2c was not possible given the lack of clear stratigraphy in the footwall. The presence of a colluvial wedge (unit $\mathrm{Cw}$ ), with internal bedding, composed of alternating fine clast-supported and silty layers covering a free face at the F2c hanging wall, just on top of clearly back-tilted thin layers of unit $\mathrm{E}$, is the evidence for another event horizon (HE3) at the bottom of unit Cw. The 0.3-m apparent thickness of unit $\mathrm{Cw}$ could be used as an approximation of the throw related to this surface-faulting event at F2c. Further evidence of this event is found at F2d where units F and E are displaced by about $0.05 \mathrm{~m}$ and warped up to the base of unit $\mathrm{D}$ that appears undisturbed.

The third fault zone (F3) is composed of five fault splays (meters 12-14; Figure 7b): three of them join in a single fault at meter 12.5 (F3a); the other two are subparallel splays near meter 14 (F3b). F3a affects the whole stratigraphy up to unit B, producing a vertical separation of unit $B$ and unit $C$ of about $0.20-0.40 \mathrm{~m}$ accompanied by a thickening of unit $B$ in the hanging wall likely due to scarp degradation. Therefore, an event horizon (HE1) can be placed again on top of unit B: This is supported also by the presence of a buried paleoscarp (top of unit B) highlighted by the thickening of the active soil (unit A) from 0.35 to about $0.6 \mathrm{~m}$, west of F3a. Moreover, along the same fault, an increase of throw with depth occurs. The contact between units $\mathrm{D}$ and $\mathrm{E}$ is displaced by about $0.60 \mathrm{~m}$, whereas the unit $\mathrm{E} / \mathrm{F}$ contact is displaced up to $0.75 \mathrm{~m}$ (Figure $\mathrm{S} 4$ ). This suggests the occurrence of a rupture (HE2) with a throw of about $0.20-0.40 \mathrm{~m}(0.60$ minus $0.20-0.40 \mathrm{~m}$, which is displacement from HE1; Table 2) during or at the end of deposition of unit D. The additional throw of the E/F contact of $0.15 \mathrm{~m}(0.75$ minus $0.60 \mathrm{~m})$, at or near the top of unit E can be related to both events HE3 and HE4. Further evidence for these events can be found at F3b. A $0.15-$ to $0.20-\mathrm{m}$ inflection occurs at the top of unit E, at meter 13.5, along with upward termination of fault F3b (HE3). One more event (HE4) can be placed at the top of unit F, which disappears below the trench bottom across F3b, with a minimum throw of about 0.35 $0.40 \mathrm{~m}$ (Figure S4). A minimum throw of $0.15-0.25 \mathrm{~m}$ is estimated for HE4 (i.e., $0.35-0.40$ minus the $0.15-$ $0.20 \mathrm{~m}$ HE3 displacement). The uncertain stratigraphic position of the HE? at F1d and F1e cannot be solved; in fact, its occurrence can be correlated with both HE3 and HE4.

Constraints on the age of the most recent (HE1) event recognized at the three fault zones are provided by radiocarbon dates on sample C202 (5890-5740 BCE) collected $0.1 \mathrm{~m}$ below unit $\mathrm{B}$ and on sample E1 (3360-3100 BCE) sampled $0.15 \mathrm{~m}$ above unit $\mathrm{B}$, at the base of the active soil (unit A). These indicate an interval of occurrence for the HE1 of 5890-3100 BCE (Figure S5).

The HE2 event horizon is located within unit D (F1c), likely close to its top (F3a); therefore, it occurred between samples C202 (5890-5740 BCE) and E3 (10590-9890 BCE). Thus, we can set the timing of HE2 in the interval 10590-5740 BCE, with the older part preferred, sample E3 being close to the event horizon. Constraints on the age of event HE3 recognized at F2, F3, and possibly F1c-d, are provided by radiocarbon dates on samples C204 (16780-16540 BCE) and C205 (19820-18990 BCE). Because sample C204 is collected within the colluvial wedge (unit $\mathrm{CW}$ ), the age of HE3 should be within the younger part of the interval 19820-16540 BCE, closer to 16780-16540 BCE. HE4 is constrained between the same samples C204 and C205 (Figure S5) and thus falls in the same age interval. On the basis of the stratigraphic locations of the samples, the oldest part of the interval is preferred (assumed to be the older half of the interval). 


\subsection{Correlation of Surface Faulting Paleo-Earthquakes Along the VBFS}

As already mentioned, the VBFS is one of the few seismogenic structures in the central Apennines that was investigated through a large number of paleoseismological trenches. Therefore, through the integration of these data, there is the occasion to build a robust and exceptionally long seismic history. The trenches from Galadini and Galli (2003) were excavated almost two decades before the occurrence of the 2016 earthquake sequence, whereas those from this work and from Galli et al. (2019) were opened in 2017. These paleoseismological data sets derive from trenches located across antithetic surface ruptures and across minor synthetic splays that ruptured the surface only in the 30 October earthquake during the 2016 sequence (Figure 1 ). In the assumption that the 2016 earthquake sequence is a reference for the surface rupture behavior of this fault system, we expect that ruptures on the antithetic fault strands and on the minor synthetic splays occur only during $\mathrm{M} \sim 6.5$ or larger earthquakes on the VBFS. Therefore, the surface faulting events discussed in the following would represent $M \geq 6.5$ earthquakes that are expected to produce a pattern of ruptures similar to that of 30 October 2016.

\subsubsection{Synthesis of Events Recognition and Dating From This Work}

The data from this work account for the earthquake history of the VBFS back to $\sim 22 \mathrm{kyr}$. As previously discussed, the Hope trench shows traces of the oldest ruptures (older than $5 \mathrm{kyr}$ ), while the two "antithetic" trenches, Curly and Matthew, describe the youngest history (the last $\sim 4$ kyr) providing fully consistent results. These circumstances allowed to compose a long paleoseismic data set for this fault system based on multiple direct evidence of surface faulting in the same trench and in different trenches.

Figure 8a synthesizes the paleoseismological results discussed above and reports a tentative correlation among the paleo-events recognized in the different trenches. This correlation is based on the preferred ages of individual events (see discussion on the single trench in sections 3.1.1, 3.1.2, and 3.2.1). When multiple age correlation was possible, we choose that one fitting better with the stratigraphy and with the events sequence in the individual trenches. From this correlation, we conclude that during the past $\sim 22 \mathrm{kyr}$ at least seven surface faulting $M \geq 6.5$ earthquakes ruptured the VBFS. These events are labeled with progressive numbers starting from the most recent event e1 (i.e., the 2016 event) to event e7. e1 (2016) is recognized as a clear rupture of the ground with throw and/or opening right on top of the fault zone, with the local exception of the Hope trench where the continuity of the 2016 ground rupture trace was lost over a few meters at the trench location. Only one more surface faulting event occurred in the past two millennia: 2 is recognized in the Matthew and Curly trenches and can be constrained in time between 260 and $590 \mathrm{CE}$. Three older events, e3 to e5, occurred between 0 and $\sim 11000$ BCE, whereas e6 and e7 date back to $\sim 17000$ and 20000 BCE. Event $\mathrm{e} 3$ is recorded in the Curly and Matthew trenches and dated to the interval 1920-50 BCE, with the older part of the interval preferred. The previous events were only found in the Hope trench, which exposes a much older stratigraphy. e4 was dated to 5890-3100 BCE; e5 was dated to 10590-5740 BCE, with the older part preferred based on stratigraphic considerations; both e6 and e7 are constrained by the same dates and occurred in the time interval 19820-16540 BCE, with a preference, based on their stratigraphic position, for the younger and older parts of the interval, respectively. There is a large time gap between e5 and e6; whether this is a true lack in surface faulting events or a lack in information (sediments missing) from the trenches cannot be established with the available data. Therefore, we consider that this paleo-earthquake history accounts for a minimum number of surface faulting events for the VBFS.

\subsubsection{Paleo-Earthquake Evidence From Other Works}

Galadini and Galli (2003) describe three trenches opened across the secondary splay crossing the Castelluccio plain (Figure 1, blue squares), in between the Matthew/Curly trench site to the north and the Hope trench site to the south. They found evidence for at least three events, here named by the label GG preceding the sequential number of the event (Figure 8a). To avoid confusion, we use the Common Era notation system for calendar era also when referring to the original ages from the authors. The most recent (at the time of 2003) event GGE1 was dated between $4155 \mathrm{BP}$ and the sixth-seventh centuries CE (i.e., 500-700 CE), the previous one GGE2 was constrained between 5940 and 3965 BP, and a previous event (or multiple events) GGE3 is poorly constrained between 18000 and 5780 years BP (Figure 8a). These three event age intervals overlap the age intervals of e2/e3, e4, and e4/e5, respectively. Unfortunately, they cannot be used to better constrain the age of these events.

Galli et al. (2019) describe three trenches (T1-T3) excavated along the same antithetic fault strand where we did excavate the Curly and Matthew trenches; T2 was very close to the Curly trench (Figure 1, green squares). These authors claim evidence for five events since 9,000 years and before 2016 . This paper would be a great 

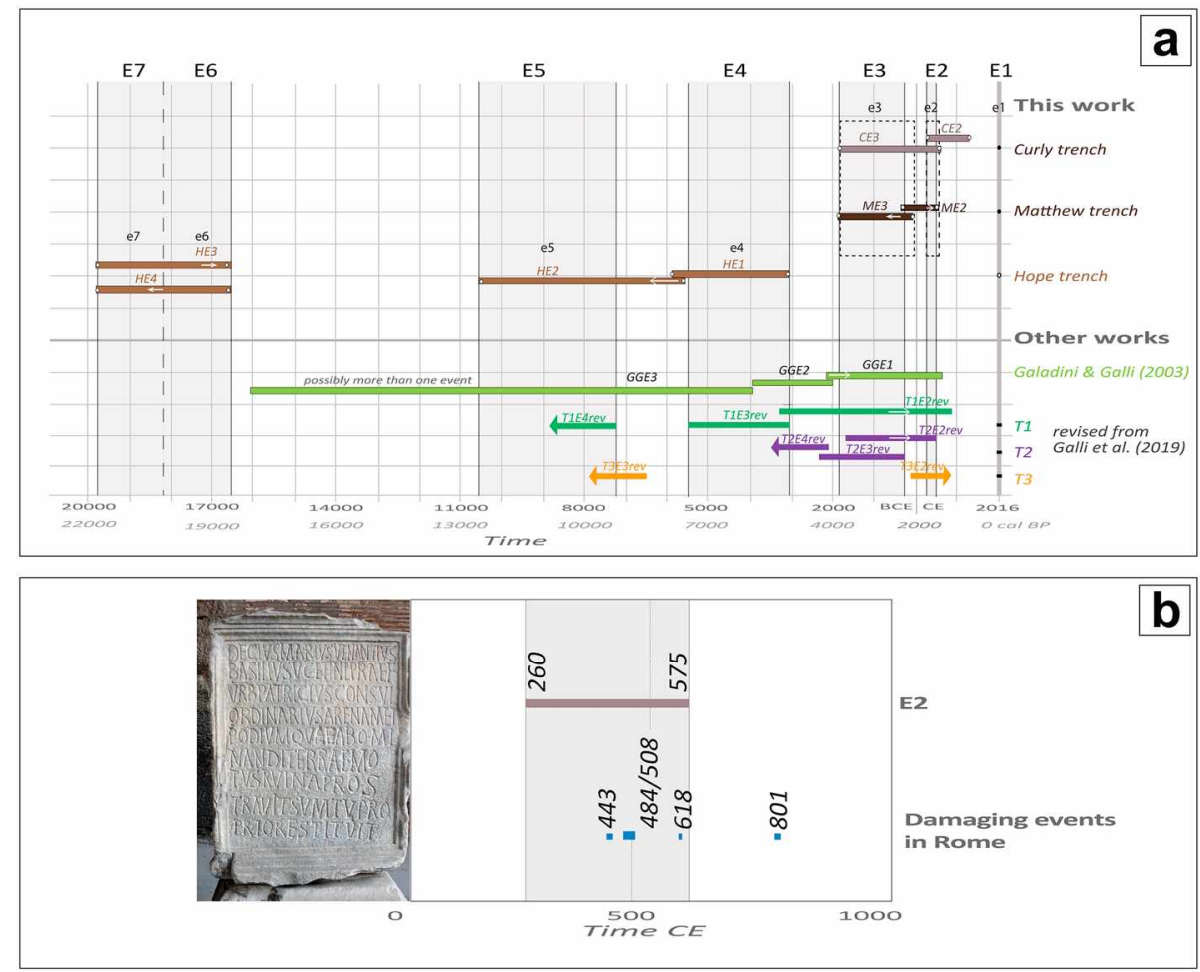

Figure 8. (a) Summary of the timing of events obtained from the trenches presented in this paper (e2-e7) and compiled from previous papers (GGE1-GGE3, T*E*rev; Galadini \& Galli, 2003; Galli et al., 2019, re-interpreted). Correlated events from all the data sets are referred to with capital letter and numbered E1 (i.e., 2016) to E7 from the youngest to the oldest. Dashed rectangles highlight correlations among results from the Curly and Matthew trenches (e2 and e3). Black circles refer to the 30 October 2016 earthquake. Horizontal bars show the uncertainties on the age of the events, and white arrows point to the preferred portion of the age interval (see section 3.3 and Table 1). The shaded vertical bands represent the preferred correlations, based on additional stratigraphic considerations when delimited by dashed lines. (b) Timing of E2 (brown horizontal bar) and damaging events documented in the ancient town of Rome in the fourth-fifth centuries CE (blue horizontal bars; Guidoboni, 1989; Guidoboni et al., 2018; see section 4.2.1 for the discussion). Photo to the left (gruntzooki. Panairjdde at it.wikipedia [CC BY-SA 2.0; https://creativecommons.org/licenses/by-sa/2.0], from Wikimedia Commons): inscription engraved in a stone near the main entrance of the Colosseum that commemorates the restoration decreed by the prefect Decio Mario Venanzio Basilio to repair the damage caused by an abominendi terrae motus, that is, an earthquake before $519 \mathrm{CE}$ when the games held in the Colosseum started again after a period of inactivity (Como, 2016).

opportunity to integrate the results of all available trenches; however, we were not able to use the results of Galli et al. (2019) as published because their concluding results are not compatible with the data they presented. The main difficulties we encountered were as follows: discussion of the event recognition was too limited, event horizons were not indicated in the logs, discussion on dated samples was very limited (i.e., lack of rationale for use or exclusion of individual samples and problems in the resulting ages with respect to the stratigraphy.), event correlation among trenches was based only on ages and not on the sequence of events, and final age ranges of events (Figure 10 in Galli et al., 2019) were much narrower with respect to the actually available age ranges (see Figure S7 and Text S1 for details).

Therefore, to assure an integration of homogeneous results, we felt obliged to reinterpret the trench logs and the dating from Galli et al. (2019), following the same approach we used for the trenches presented in this work, mainly being conservative and trying to avoid overinterpretations of the data. On the basis of this reinterpretation, the pre-2016 event T1E2rev/T2E2rev/T3E2rev is recognized in all three trenches and can be dated to $340-575 \mathrm{CE}$. A previous event T2E3rev is seen only in T2 and can be dated to 4520 2365 BP. Two older events, inferred by the correlation of T2E4rev/T1E3rev and T3E3rev/T1E4rev, are dated to $7710-5055 \mathrm{BP}$ and before $9130 \mathrm{BP}$, respectively (lower part of Figure 8a; see also Figure S7 and Text S1). 


\subsubsection{Integrated History of $M \geq 6.5$ Surface Faulting Earthquakes Along the VBFS}

Figure 8a shows that a good correlation exists between the chronology of surface faulting events from the three sets of trench data (e1-e7, GGE1-GGE3, T*E*rev; see sections 3.3.1 and 3.3.2), making particularly reliable the surface faulting history for $M \geq 6.5$ earthquakes along the VBFS. Age ranges of events (referred with capital letter and numbers, E1-E7) obtained by integrating the three works are listed in Table 3 and are graphically highlighted with shaded vertical bands in Figure 8a.

\section{Discussion}

\subsection{Paleo-Earthquake Size}

We recognized evidence for the occurrence of seven surface faulting earthquakes between $\sim 22 \mathrm{kyr}$ and 2016 along the VBFS. The magnitude of these events is expected to be similar to or larger than that of the 30 October 2016 earthquake $(M \geq 6.5)$ because we trenched those fault splays that ruptured only during the 30 October 2016, Mw 6.5 earthquake and were not involved in the previous surface faulting events of 24 August (Mw 6.1) and 26 October (Mw 5.9; Figures 1, 2, and S2). In fact, the 30 October earthquake produced not only a longer surface rupture but also a wider deformation zone with the occurrence of displacement on antithetic and secondary synthetic strands (Civico et al., 2018; Villani, Civico, et al., 2018; Villani, Pucci, et al., 2018).

In the trench walls, most of the displacements measured for individual paleo-events are distributed over several fault splays, and the throw values lead to paleorupture sizes comparable to or larger than that of 2016 (Table 2), suggesting $M \geq 6.5$ events. The throw of individual paleo-events at the San Lorenzo site is obtained by summing the values at the two trenches, because these are located across two overstepping and structurally linked strands, PRA1 and PRA2 (Figures 2a and 3). Indeed, by summing the 2016 vertical displacements measured at the Curly (CE1, 0.04-0.10 m) and Matthew (ME1, 0.42-0.49 m) trenches, we estimate an average throw on the antithetic fault relay of $0.52 \pm 0.03 \mathrm{~m}$ (E1, Table 2). In a similar way, the sum of the vertical displacements of E2 measured at the Curly (CE2, 0.12-0.21 m) and Matthew (ME2, 0.46-0.49 $\mathrm{m}$ ) trenches provides the average throw of the penultimate event along the same relay zone, that is, 0.65 $\pm 0.06 \mathrm{~m}$ (E2, Table 2). The total throw per event of E1 and E2 is thus comparable. In both events, the vertical displacements in the Curly trench are smaller, contributing $\sim 15 \%$ and $\sim 35 \%$ of the total amount across the two splays in E1 and E2, respectively. We could not retrieve the throw value of ME3 at the Matthew trench, but as a first approximation, we consider the CE3 throw value $(0.05-0.14 \mathrm{~m})$ as a minimum value for ME3. Again, summing the throws in both trenches, a minimum average throw for $\mathrm{E} 3$ of $0.20 \pm 0.04$ $\mathrm{m}$ is inferred on the antithetic fault (E3, Table 2). The paleothrows from trenches are point observations, but they appear to be representative of the amount of throws recurring along the antithetic zone (Figure 2a). Indeed, they are of the same order of magnitude as the 2016 average throw calculated for the antithetic splays, which is $0.41 \mathrm{~m}$ (Villani, Pucci, et al., 2018). Moreover, the coefficient of variation (standard deviation divided by the mean) of the E1-E2-E3 displacements is $\sim 0.40$, indicating that the values have a low average variation and are characteristic for the site (see also Hecker et al., 2013). These congruences also allow us to consider that the amount of slip per event of paleo-earthquakes captured in the trenches depicts a large percentage of the total vertical displacement occurring on the antithetic fault splays (i.e., major displacement is usually partitioned in the discrete zone with trench-spatial extent of meters) and that only a small amount occurs away from this zone (see also Wedmore et al., 2019). The paleothrows on the antithetic fault (Table 2) are likely to be considered minimum estimates on the master fault at this location (Mt. Porche-Mt. Argentella, POR1 and POR2 in Villani, Pucci, et al., 2018; Figure 2a). The Hope trench provided estimates of the throw associated with E4 to E7 for the secondary synthetic splay. At the trench location, the average throws for the individual events are $0.55 \pm 0.07 \mathrm{~m}(\mathrm{E} 4), 0.30 \pm 0.06 \mathrm{~m}$ (E5), $0.48 \pm 0.01 \mathrm{~m}$ (E6), and $0.35 \pm 0.03 \mathrm{~m}$ (E7, Table 2). As for the previous trench site, the coefficient of variation of the displacements is $\sim 0.30$.

We cannot directly compare the paleodislocations and the 2016 throw (not available; see section 3.2) at the Hope trench site. However, an average vertical displacement of $0.07 \mathrm{~m}$ is recorded along the 2016 rupture strand of Forca di Presta (Figures $2 \mathrm{~b}$ and $10 \mathrm{~b}$ ). Assuming this average throw to be representative of the trench site, the average throws of E4 to E7 paleo-events (Table 2) are significantly higher. Three main reasons can explain this variability of the throw per event in time at this site: (1) the large values possibly 
Table 3

Summary of the Parameters Calculated for the Paleoearthquakes and Fault Slip Rates

\begin{tabular}{|c|c|c|}
\hline \multicolumn{3}{|l|}{ Events Timing } \\
\hline Event & Integrated age ranges & Correlated events \\
\hline E1(Antithetic) & 2016 & \\
\hline E2(Antithetic) & 260-575 CE (preferred $433 \mathrm{CE}$ ) & $\begin{array}{l}\text { CE2, ME2, T1E2rev, T2E2rev, T3E2rev, } \\
\text { GGE1? }\end{array}$ \\
\hline E3(Antithetic) & 1930-415 BCE & CE3, ME3,T2E3rev \\
\hline E4(Synthetic) & 5760-3100 BCE & HE1, T2E4rev, T1E3rev, GGE2 \\
\hline E5(Synthetic) & $10590-7180 \mathrm{BCE}$ & HE2, T1E4rev, T3E3rev, GGE3? \\
\hline E6(Synthetic) & 19820-16540 BCE (preferred 18180-16540 BCE) & HE3 \\
\hline E7(Synthetic) & 19820-16540 BCE (preferred 19820-18180 BCE) & HE4 \\
\hline \multicolumn{3}{|l|}{ Recurrence Interval } \\
\hline Number of inter-event & Probability distribution & Inter-event (median value) \\
\hline Iev1,2 (E1-E2) & ${\text { uniform} / \text { degenerate }^{\mathrm{a}}}$ & $1440-1755(1560) / 1573^{\mathrm{a}}$ \\
\hline Iev2,3 (E2-E3) & trapezoidal/uniform $^{\mathrm{a}}$ & $675-2505(1590) / 860-2375(1615)^{\mathrm{a}}$ \\
\hline Iev $3,4(E 3-E 4)$ & trapezoidal & $1170-5345(3260)$ \\
\hline $\operatorname{Iev} 4,5(E 4-E 5)$ & trapezoidal & $1420-7490(4460)$ \\
\hline Iev $5,6(E 5-E 6)$ & 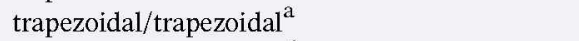 & $5950-11000(8480) / 5950-11000(8475)^{a}$ \\
\hline Iev6,7 (E6-E7) & trapezoidal/asymmetric ${ }^{\mathrm{a}}$ & $0-3280(2137) / 0-3280(1640)^{\mathrm{a}}$ \\
\hline \multicolumn{3}{|l|}{ Slip Rate } \\
\hline Fault splay (code) & Vertical slip rate $(\mathrm{mm} / \mathrm{yr})$ & Dip slip rate $(\mathrm{mm} / \mathrm{yr})$ \\
\hline $\begin{array}{l}\text { Mt. Rotondo-San Lorenzo-Ghezzi (PRA1-PRA2) } \\
\text { Antithetic fault }\end{array}$ & $0.24-0.35^{\mathrm{b}}$ & $0.26-0.38^{\mathrm{b}}$ (minimum calculated) \\
\hline Mt. Porche-Mt. Argentella (POR1-POR2) Master fault & & $0.22-0.36^{\mathrm{b}}$ (minimum inferred) \\
\hline Forca di Presta (VET6) Synthetic fault & $\sim 0.10^{\mathrm{c}}$ & $0.10-0.11^{\mathrm{c}}$ \\
\hline
\end{tabular}

Note. Timing of events: age ranges are based on the preferred ages (see also Figure 8a) and derived by the correlation of single events in multiple trenches; Recurrence interval: results of statistical analysis of inter-event times (Iev) based on different type of probability distribution (see section 4.2 for details); Slip rate: minimum slip rates for the central and southernmost portion of the VBFS derived from Matthew-Curly and Hope trenches.

${ }^{\mathrm{a}}$ Data obtained assuming $433 \mathrm{CE}$ as occurrence time of E2 and using the preferred intervals of E6 and E7. ${ }^{\mathrm{b}}$ Rate from Matthew and Curly trench data.

${ }^{\mathrm{C}}$ Rate from Hope trench data.

include throws from more than one event; (2) the different throw per event at the trench scale may result from the breakage of different slip patches on the fault at depth or different rupture dynamics during individual paleo-events on the VBFS; and/or (3) the E4 to E7 are displacements from $\mathrm{M}>6.5$ earthquakes, larger than the 2016 earthquake. All three cases lead to a different rupture scenario compared to the 2016 rupture along the southern portion of the VBFS. Along this portion, the 2016 throw decreases and the rupture trace becomes discontinuous, until it finally disappears about $1 \mathrm{~km}$ to the south. In contrast, the larger throws of the paleoruptures at the Hope trench location possibly indicate the rupture of a longer fault system, suggesting a linkage between the VBFS and the southern contiguous fault system, that is, the Mt. Laga fault system (LMFS; Figure 1), giving rise to higher-magnitude events. The VBFS and the northernmost portion of the LMFS already ruptured together, producing the Mw 6.1, 24 August 2016, Amatrice earthquake (Chiaraluce et al., 2017). However, the rupture at surface was confined along the southernmost part of the VBFS (Figure S2) with average slip $\sim 0.13 \mathrm{~m}$ and not involving the splay south of Forca di Presta (VET6), thus picturing a scenario not congruent with our paleoseismic data. The relatively large paleothrows at the Hope trench location would imply a rupture involving the southern section of the VBFS (splays VET6 and VET7) together with a larger portion of the LMFS in the period between 5 and $22 \mathrm{kyr}$. The paleoseismic data collected along this southernmost portion of the fault system would also be concordant with the fault linkage hypothesis proposed by Pizzi et al. (2017). Further data, including the timing and the size of paleoruptures along the northern portion of the Laga fault, are needed to corroborate this hypothesis.

Our chronological correlation of surface faulting events from the three sets of trench data (see section 3.3.3 and Figure 8a) allows some considerations on the minimum length of the paleoruptures. The three (E2-E4), 
possibly four (E2-E5), surface ruptures before 2016 contemporaneously involved different splays of the fault system, in both the central and southern portions, spanning a distance of $10 \mathrm{~km}$. This value can be considered the minimum rupture length for the Holocene paleo-events recognized along the VBFS so far.

As a general comment, the analysis of slip variation in different events at a point may be helpful to constrain the intrinsic variability in the range and frequency of earthquake sizes produced by a fault system. On the other hand, multiple trenching sites are required along strike to reduce the uncertainties on paleomagnitudes, along with fault geomorphological observations (i.e., fault length and medium- to long-term slip rate).

\subsection{Recurrence Interval}

The overall average recurrence interval of surface faulting along the investigated portions of the VBFS is in the range 3360-3640 years (seven events since 19820-18180 BCE; Table 3). Recurrence intervals of thousands of years for surface faulting events are typical of the major normal faults in the central Apennines (e.g., Cinti et al., 2018; Galadini \& Galli, 1999; Galli et al., 2008; Pantosti et al., 1996). However, using the time window of the last $\sim 4,000$ years, the average interval is 1,220-1,970 years (three events since 1930$415 \mathrm{BCE}$ ), which is substantially shorter (Table 3 ).

To analyze this issue more in detail, we estimate the probability distribution of the interevent time (Iev) related to each couple of consecutive events. Specifically, for the interevent time $\operatorname{Iev}_{i, j}$, we simulate $10^{7}$ couples of occurrence times of temporally adjacent events $E i$ and $E j$, drawn from a uniform distribution of the respective event ages (Table 3 ). Then the probability distribution for $\operatorname{Iev}_{i, j}$ is given as the empirical distribution of simulated interevent times. In this way, we obtain trapezoidal distributions for all Iev, but the most recent $I_{1,2}$, for which we have a uniform distribution (Figure 9a). Table 3 lists the time ranges for all Iev, together with related median times. We repeat the same analysis by assuming as alternative hypothesis the preferred intervals for E2, E6, and E7 (Table 3).

The obtained irregular distribution of the earthquake recurrence over a timescale of thousands of years can be explained in different ways. On the one side, it may be affected by a bias in the data collection over time. In fact, the further we go back in time, the higher the probability that we missed traces of individual events of surface faulting (as depositional and erosional processes may have overridden them). This is particularly true in a monotonous stratigraphy like that exposed in the Hope trench, with depositional/erosional processes strongly influenced by climate, landscape, and karst. Moreover, the time window 13-19 kyr lacking any events coincides with the late glacial period that was generally characterized by very low depositional rates, making very hard to recognize individual faulting events with throws similar to the 2016 earthquake (minor signature in the Hope trench) or even with throws of several tens of centimeters. This may also explain the highest throw values measured for the old events. On the other side, we could hypothesize that since the Late Holocene, the VBFS has experienced an acceleration of the seismic release with shorter interevent time between surface rupturing earthquakes. If we assume that the irregular distribution of the earthquake recurrence is due to a natural variability, instead of bias in the data, we can estimate an overall probability distribution for Iev, by means of simulation, as we did to determine the individual Iev. The resulting distribution is shown in Figure $9 \mathrm{~b}$ (blue solid line), giving a probability close to 0.6 of having an Iev $<3,000$ years and the most likely Iev close to 2,000 years. In the hypothesis of a renewal behavior (i.e., that the intervals between successive events are independent and identically distributed), this type of distribution predicts a possible long-term temporal clustering of surface faulting earthquakes, on a timescale of thousands of years. We repeat the same procedure, both by considering the preferred events ages (Table 3 ) and by separating the interevents computed on the Curly-Matthew (E1-E3) and Hope (E4-E7) events. Whereas the two versions of event dating (Table 3) do not provide significant differences in the overall probability distribution of Iev (Figure 9b, solid and dashed blue lines), the separation of interevents derived by distinct trenches provides quite different distributions for Iev (Figure 9b, red and black solid lines). Specifically, the possible values of Iev for the Hope events (black solid line) cover a well larger range (up to 10,000 years) than that given by the Curly-Mattew events (red solid line, recurrence time below 3,000 years).

Variable fault recurrence intervals are a common feature of other extensional environments (e.g., Akcar et al., 2012; Friedrich et al., 2003; Nicol et al., 2016) and already documented for the Paganica fault, rupturing in the $2009 \mathrm{Mw}$ 6.1 L'Aquila earthquake (Cinti et al., 2011) in the central Apennines. Such temporal variability could be the result of interactions between active faults within distributed fault networks, despite the fact 

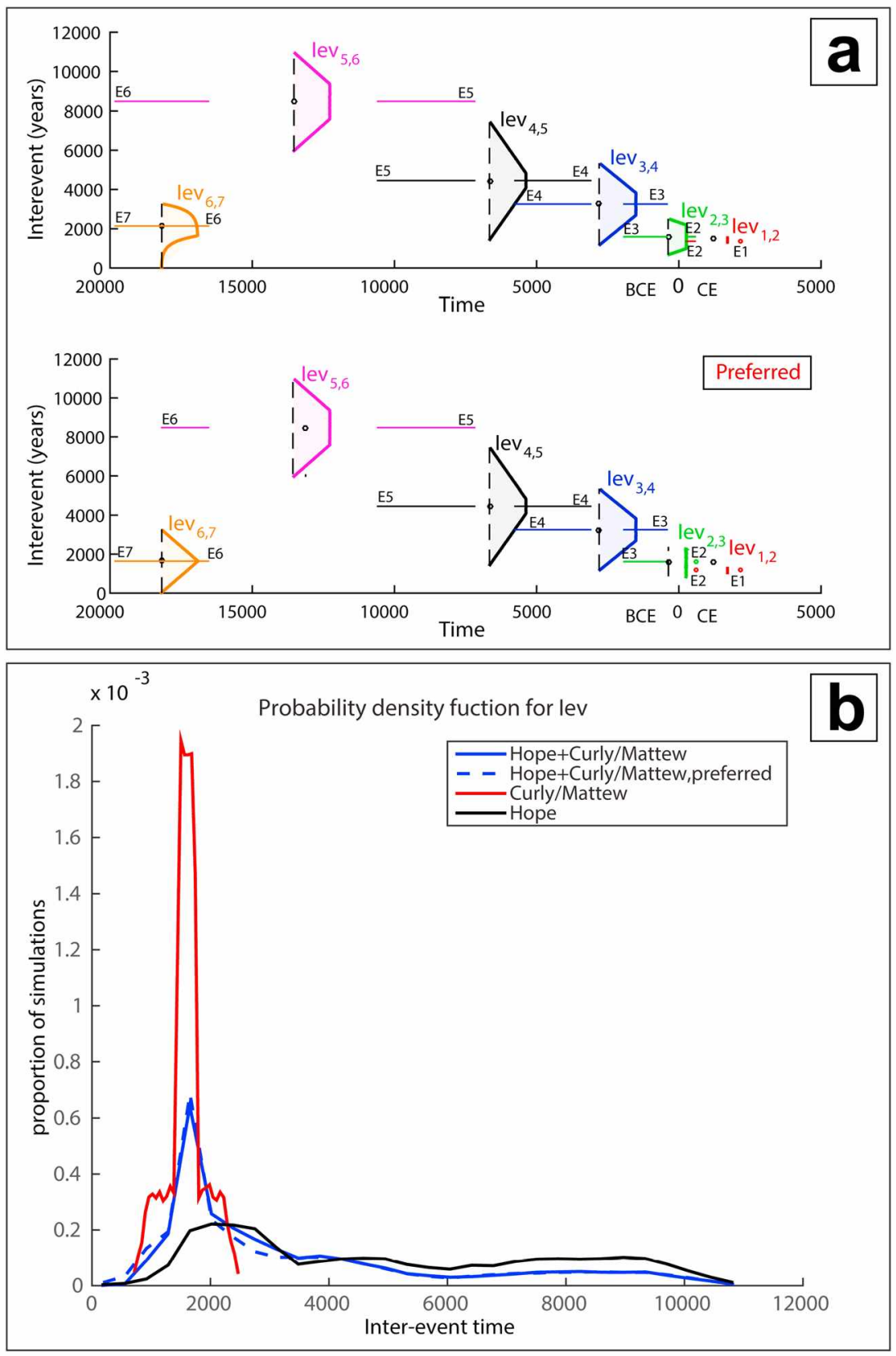

Figure 9. (a) Plot of probability distributions of interevent times (Iev). Bottom panel refers to preferred age intervals (Table 3). For each Iev, solid horizontal lines mark the interval times for the bounding events. The vertical dotted black lines mark the estimated interval times of the corresponding Iev (see also Table 3). The adjacent shaded areas mark the estimated probability density function of each Iev (uniform for $\operatorname{Iev}_{1,2}$ and trapezoidal for all the others). The dots mark the median points between the representative times (i.e., central point of estimated interval times) of subsequent events. (b) Overall probability density function for Iev, obtained by integrating the distributions shown in Figure 9a by mean of simulations. Colors mark the different age interval data sets.

that the tectonic loading rate may be constant in time and space (e.g., Cowie et al., 2012; Marzocchi et al., 2009; Marzocchi \& Melini, 2014; Robinson, 2004; Robinson et al., 2009; Wedmore et al., 2017). Another factor, commonly invoked to explain the irregular recurrence of faults, is the role played by fluids in the fault failure process, as suggested for the 2016 seismic sequence by Walters et al. (2018). The role of fluid migration appears to be relevant for the Apennines and was also observed in the nucleation and evolution 
of the 2009 L'Aquila earthquake sequence (Di Luccio et al., 2010; Lucente et al., 2010) and the 1997 Colfiorito sequence (Miller et al., 2004).

Moreover, we have also to consider that our history of past rupturing events may include some smaller events (24 August and 26 October 2016 type) that we could not decipher because they are too small and close in time (overridden; see also section 2.). Then, the slip interpreted as formed in a single discrete event would be a cumulative slip in more than one event and the interevent time would be shorter. This is unlikely for the Curly and Matthew trenches where the throw is comparable for all recognized events, including the 2016 earthquake (Table 2). Conversely, at the Hope trench, we have to consider the possibility that the large observed throws contain also some minor ruptures that cannot be individually constrained (four events produced a total of $1.68 \mathrm{~m}$ versus the about $0.07 \mathrm{~m}$ offset in 2016). The complexity of the Hope trench setting is also highlighted by the fact that the 2016 rupture did not intersect the trench (possibly because of rupture migration toward the doline; Figure 6).

4.2.1. Paleoseismological Data Versus Historical Accounts

Event E2 was dated between 260 and 575 CE (Figure 8). Several earthquakes struck Rome between the fifth and ninth centuries CE (Figure $8 \mathrm{~b}$ ) as testified by historical sources that document earthquake damage and subsequent reconstruction (Galli \& Molin, 2014; Guidoboni, 1989; Guidoboni et al., 2018). In particular, the pieces of evidence of coseismic collapse and destruction are distinct and have been chronologically attributed to earthquakes in CE 443, 484-508 (uncertain date), and 801 (e.g., Galadini et al., 2018). The effects of seismic shaking were severe (7.5-8 intensity degree MCS in Rome; Guidoboni et al., 2018) and likely aggravated due to the high vulnerability of the buildings at that time. The main cause for the shaking in Rome are the $\mathrm{M}>5.5$ earthquakes originating on the dense network of active faults in the central Apennines (e.g., Galli \& Molin, 2014). Some of these earthquakes have been attributed to specific faults. Moving in the modern era, we witnessed the activation of multiple distinct faults producing earthquakes in a close temporal succession, that is, Fucino 1915, Umbria-Marche 1997, L'Aquila 2009, and Norcia 2016: All these events were felt in Rome with assigned intensity $\geq 5$ MCS. Therefore, the temporal clustering of seismicity highlighted by the historical documentation of Rome is likely contained in the paleoseismological records of the faults in the central Apennines. Paleoseismic investigations have significantly increased our knowledge of the seismic history of these faults in the last decades; nevertheless, the correlation between paleo-earthquakes recorded in trenches and historical events is still made difficult by the limited historical observation before 1600 , by the limited record of paleoearthquakes with respect to known active faults, and also because of the large uncertainty in the timing of events. In fact, even when the paleo-earthquake age interval is relatively narrow and based on absolute dating, it remains on the order of a few hundred years, a time window large enough to include more than one historical earthquake.

Based on the trenching data available in the literature, several faults in the central Apennines can be responsible for the damage in Rome between the fifth and ninth centuries CE.

However, it is interesting to note that the age we obtain for E2 on the VBFS overlaps with two damaging events recorded in Rome, located about $120 \mathrm{~km}$ southwest, and dated 443 and 484/508 CE (Figure 8b). These events produced collapses of temples, homes and public buildings, and colonnades and heavy damage affecting the Flavio amphitheater (Galadini et al., 2018; Guidoboni et al., 2018). On the basis of paleoseismological and archeoseismological evidence, the $484 / 508 \mathrm{CE}$ event has been tentatively attributed to the Fucino fault that lately ruptured in 1915 (e.g., Galadini et al., 2010; Galadini \& Galli, 1999).

Assuming the 484/508 CE earthquake indeed occurred on the Fucino fault, the Mw 6.5, 30 October 2016 earthquake ( 5 intensity degree EMS-98 in Rome; Rossi et al., 2019) can be interpreted as a modern twin of the $443 \mathrm{CE}$ event. This interpretation is in agreement with that in Galli et al. (2019), concluding that the penultimate earthquake on the VBFS occurred in Late Roman times, perhaps in $443 \mathrm{CE}$.

It is interesting to note that similar to what happened during the past 30 years with the clustered occurrence of three main seismic sequences on neighboring faults (1997, 2009, and 2016), the central Apennines did already experience an Early Middle Age seismic cluster producing significant impact on the town of Rome (CE 443, 484/508, and 801).

The comparison of the ages of the paleo-earthquakes collected in trenches across neighboring faults to those of the VBFS (Table 3) may help in unraveling the pattern of paleotemporal clustering in the area. Of course, the more robust is the age constraint of the paleo-events, and the more reliable is the comparison. As an 

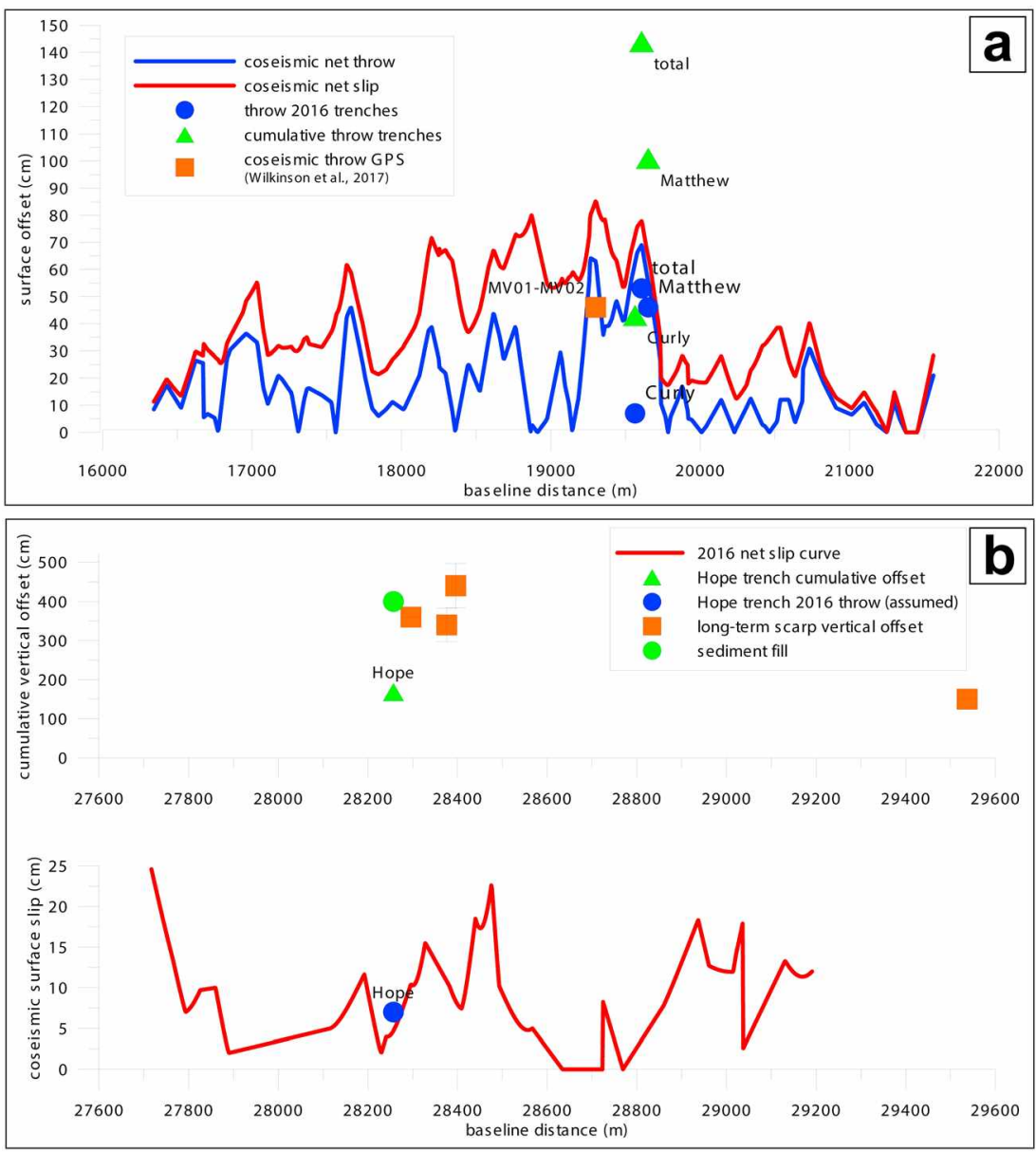

Figure 10. (a) Comparison between the individual and cumulative coseismic throws recovered in the Matthew and Curly trenches (blue circles $=2016$ throw; green triangle $=$ cumulative throw of paleo-events E1, E2, and E3, $1.37 \pm 0.8 \mathrm{~mm}$ ) and the 2016 Norcia earthquake coseismic net throw (blue line) and net slip (red line) for the conjugated fault set in the central portion of the Mt. Vettore-Mt. Bove fault system (splays POR1, POR2, PRA1, and PRA2) averaged within 100-m-long moving windows and projected onto a common $\mathrm{N} 155^{\circ}$ trending baseline (from Villani, Pucci, et al., 2018). The orange square reports the differential coseismic vertical displacement measured by GPS receivers MV01 and MV02 of Wilkinson et al. (2017) during the Norcia earthquake. (b, bottom) Paleoseismic throw data from the Hope trench (blue circle = assumed value for the 2016 throw) compared to the coseismic net slip of the 2016 Norcia earthquake along the VET6-VET7 splays (red line); (top) long-term vertical offset obtained from the total throw in the trench (green triangle; $1.68 \pm 0.1$ ), from topographic profiles (orange squares, with error bars shown) and from the inferred low-resistivity sediment infill in the trench site (green circle).

example, a paleo-event just before $3800-3600 \mathrm{BP}(1650-1850 \mathrm{BCE})$ has been associated with the Norcia fault running parallel to and just to the west of the VBFS (Galli et al., 2018). The timing of this event overlaps with that of $\mathrm{E} 3(1920-1500 \mathrm{BCE})$ along the VBFS. Thus, it is possible that these two events are two successive, and close in time, earthquakes occurring in the area on distinct nearby faults, as part of a previous cluster of paleoearthquakes.

\subsection{Late Pleistocene-Holocene Dip-Slip Rates}

Data from the trenches allow us also to make some considerations on the slip rates of the VBFS for the Late Pleistocene-Holocene.

In order to infer the slip rate of the central portion of the fault system activated during the Norcia earthquake, we consider the pinpoints from the Matthew and Curly trenches, namely, the aggregate average throws of the 2016 event $(\mathrm{E} 1: 0.52 \pm 0.03 \mathrm{~m})$, the cumulative minimum throw value of the three most recent events (E1, E2, and E3: $1.37 \pm 0.08 \mathrm{~m}$; Figure 10a), and the resulting average throw per event $(0.46 \pm 0.03 \mathrm{~m})$. If we average the 30 October 2016 surface throw along strike and attribute it to the trenched antithetic faults (splays PRA1 and PRA2), we obtain $0.41 \mathrm{~m}$. This averaged 2016 throw is similar to the average throw per 


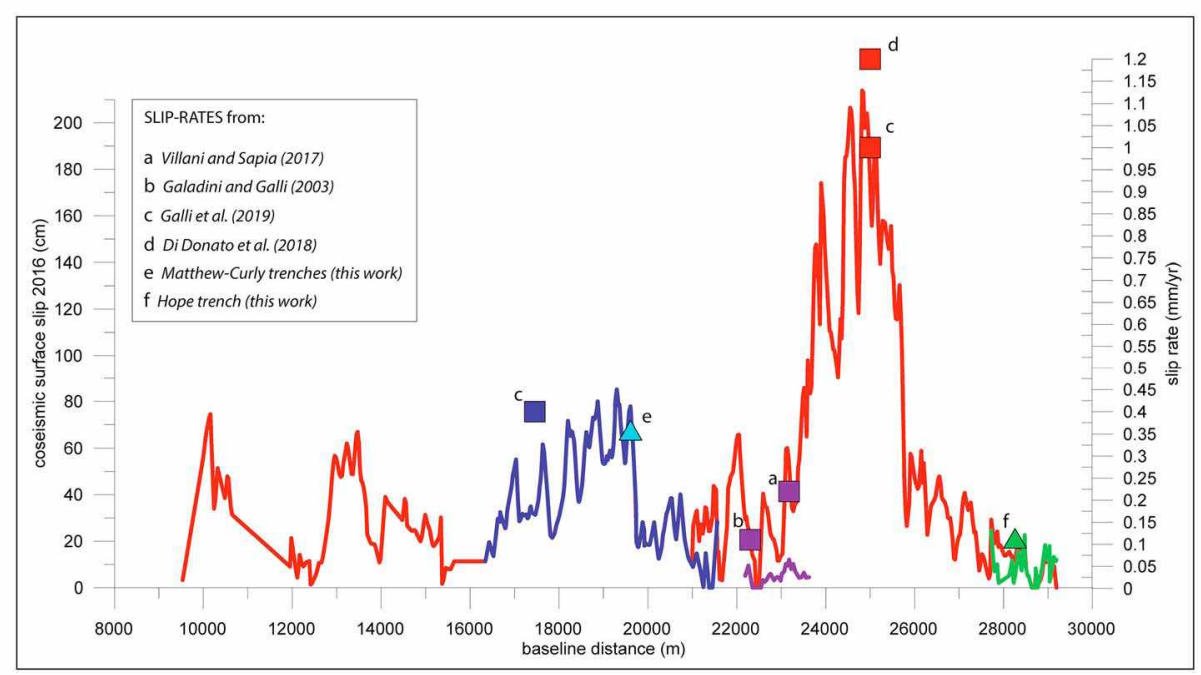

Figure 11. The 2016 coseismic surface slip versus slip rates along the Mt. Vettore-Mt. Bove fault system. The red curve is the net surface slip of the Norcia earthquake (Villani, Pucci, et al., 2018); the blue curve is the net slip of the PRA1-PRA2POR1-POR2 splays; the green curve is the surface slip of the VET6-VET7 splays; and the purple curve is the surface slip within the Castelluccio plain (VET1 in Villani, Pucci, et al., 2018). The symbols of squares and triangles refer to Late Pleistocene to Late Holocene minimum slip rates available in the literature and estimated in this work, respectively (see inset). Each of the rate values refer to distinct splays of the system, and symbols have the same color as the corresponding surface slip curve. Surface slip curves are scaled in order to be compared with the slip rates in the same plot.

event from trenches $(0.46 \pm 0.03 \mathrm{~m})$, suggesting a quasi-characteristic slip for the past three events. On the basis of outcropping bedrock fault planes, the semigraben formed by synthetic (POR1 and POR2) and antithetic (PRA1 and PRA2) splays is nearly symmetrical, showing planes dipping $61-68^{\circ}$ and $64^{\circ}$, respectively (data from Villani, Civico, et al., 2018). Thus, using the average interval of 1,220-1,970 years (see section 4.2) for the last three interevents and the average throw per event $(0.46 \pm 0.03 \mathrm{~m})$, we estimate a vertical slip rate of at least $0.24-0.35 \mathrm{~mm} /$ year on the antithetic fault (Table 3). Taking into account a fault dip of $64^{\circ}$, the resulting dip-slip rate is in the range of $0.26-0.38 \mathrm{~mm} /$ year. Moreover, assuming that the master fault displays a deformation equal or larger than the antithetic structure, this range represents a minimum for the slip rate expected on the master fault at this location (Mt. Porche-Mt. Argentella, POR1 and POR2, in Villani, Pucci, et al., 2018; Table 3 and Figure 11).

In order to evaluate a vertical slip rate based on the Hope trench data, we use the average throw per event of $0.42 \pm 0.02 \mathrm{~m}$ (HE1 to HE4 throw values; Table 2) and the average recurrence interval of 4,140-5,570 years, derived for E4 and E7 (time window 12,400-16,700 years, Table 3). The resulting vertical slip rate is $\sim 0.10$ $\mathrm{mm} /$ year (Table 3). Assuming a fault dip ranging $65-75^{\circ}$ (from fault-plane dip measurements from Villani, Civico, et al., 2018), we obtain a dip-slip value of $0.10-0.11 \mathrm{~mm} /$ year (Table 3 and Figure 11). This value is representative of the southernmost tip of the fault system (south of Forca di Presta; Figure 2), and it is a minimum value for the whole southern portion of the VBFS, including at least one additional subparallel splay (VET7 to the east; Figure 1).

The total 2016 throw from the Matthew and Curly trenches $(0.52 \pm 0.03 \mathrm{~m})$ is comparable to the average coseismic net throw $(0.50 \mathrm{~m})$ calculated within a $250-\mathrm{m}$-long fault section including the trenches (Villani, Pucci, et al., 2018). This confirms that the two trenches provide quasi-complete information on the coseismic slip along this complex fault system (Figure 10a). Not having a complete field data set of the total 2016 throw on the synthetic fault zone facing the trench location, we can use the 0.46-m coseismic near-fault POR1 vertical displacement (Figure 10a), measured by low-cost GNSS receivers located about $1 \mathrm{~km}$ to the NE of our trench sites (Wilkinson et al., 2017). The total coseismic throw of $0.52 \mathrm{~m}$ recovered in the Matthew and Curly trenches, as the value of the local graben subsidence, is slightly larger than this value. This supports the hypothesis that part of the surface faulting along the synthetic zone is missing or widely distributed and was not covered by field surveys. In fact, the near-field GNSS measurement at this location also 
belongs to a single synthetic splay (Wilkinson et al., 2017), while the synthetic fault system likely accommodates a much larger subsidence of its whole hanging wall at a broader scale.

Finally, we provide some clues on the age of the trenched fault splays based on morphological considerations. We may consider the Mt. Rotondo-Mt. Abuzzago ridge bounding to the west the graben area of San Lorenzo basin (Figures $2 \mathrm{a}$ and 3 ) as the geomorphic signature of the long-term activity of the antithetic fault running along its slope. Then, using the topographic throw of the ridge (ranging between 80 and $120 \mathrm{~m}$ ) and the minimum vertical slip rate of the antithetic fault obtained from trenching $(0.24-0.35 \mathrm{~mm} /$ year $)$, we infer a rough minimum age for the ridge growth of $330-340 \mathrm{kyr}$. This value would suggest a relatively youthful inception of the graben formation, that is, of the antithetic fault activity (Middle Pleistocene age).

Similarly, for the Hope trench, we compare our data with the cumulative scarp height obtained using serial topographic profiles from a high-resolution digital elevation model, where it is well preserved and continuous (Figure 10b). This provides a minimum estimate of the total topographic throw accrued by splay VET6, which is about $3.2 \mathrm{~m}$ on average (the obtained scarp height ranges from 1.5 to $5.2 \mathrm{~m}$ ). If we use the vertical slip rate obtained from trench data $(\sim 0.10 \mathrm{~mm} /$ year $)$, in the assumption of constant rate, we infer that this fault scarp is likely $32 \mathrm{kyr}$ old. We also note that the total amount of sediment (about $4 \mathrm{~m}$ ) trapped by the VET6 splay in the Hope trench site as inferred from our electrical resistivity tomography model (conductive material in Figure 6c) provides an indirect estimate of the local minimum long-term throw, which is consistent with the topographic data. Additionally, assuming a constant sedimentation rate (about 0.09 $\mathrm{mm} /$ year, from the position of sample $\mathrm{C} 205$ that is $1.8 \mathrm{~m}$ below the ground surface; see Figure 7 ), the resulting inception age of the damming is $44 \mathrm{kyr}$, consistent with the inferred age of the fault scarp. This estimate points to a Late Pleistocene formation of the antislope scarp. The youthfulness of the southernmost part of the fault system, along with the large paleothrows recognized in the Hope trench, would further support the hypothesis that VET6 is propagating to the south following the linkage between the VBFS and the LMFS (see also section 4.1).

Other values of Late Pleistocene-Holocene slip rate for distinct parts of the VBFS (Figure 11) have been obtained: (1) from trenching, electrical resistivity tomography investigation, and topographic leveling across the westernmost SW dipping splay (minimum $0.11 \mathrm{~mm} /$ year in the late Holocene; Galadini \& Galli, 2003; $0.22 \pm 0.07 \mathrm{~mm} /$ year post-23 kyr; Villani \& Sapia, 2017) in the Castelluccio plain; (2) from trenching across the antithetic splay (minimum $0.4 \mathrm{~mm} /$ year in the last $30 \mathrm{kyr}$; Galli et al., 2019); (3) from geomorphological investigation across the Mt. Vettore fault $(\sim 1 \mathrm{~mm} /$ year in the last $30 \mathrm{kyr}$; Di Donato et al., 2018; Galli et al., 2019). The slip rate evaluations belonging to the same splay of the system are within the same order of magnitude and are comparable to those of other active fault systems in the central Apennines, which are generally around 0.3-0.4 mm/year in the Holocene (e.g., Cinti et al., 2018; Galadini et al., 2003; Galli et al., 2018; Michetti et al., 1996; Moro et al., 2016; Pantosti et al., 1996; Salvi et al., 2003). In order to obtain a value representative for the activity of the VBFS, these estimates should be considered within a reference frame reconciling both the coseismic slip and the long-term deformation. As shown in Figure 11, the average trend of the net slip and throw on 30 October 2016 is well reflected in the paleoseismologically and geomorphologically derived Late Pleistocene-Holocene rates.

\section{Conclusion}

The analysis and integration of paleoseismic data sets acquired so far along the VBFS provide an original reconstruction of the Late Pleistocene-Holocene seismic history of the fault system rupturing on 30 October 2016. The data sets include a total of nine trenches, three from this work and six from previous ones (Galadini \& Galli, 2003; Galli et al., 2019). Five trenches were opened across the antithetic splays in the central portion of the 2016 surface rupture, three trenches were located within the Castelluccio plain along the 2016 secondary synthetic splay, and one more was at the southernmost tip of the 2016 rupture trace also along a synthetic splay.

We performed a detailed paleoseismological analysis of the three trenches presented in this work by determining the amount of throw and timing for each paleo-event. The occurrence of each event was defined by the presence of multiple evidence in each trench. Then, after a thorough review of all the preexisting data, we interpreted and correlated events among all available trench sites and obtained recurrence interval estimates and Late Pleistocene and Holocene slip rates. 
The main findings of this study can be summarized in the following points:

1. The 2016 surface rupture coincides with mainly normal, high-angle-dipping fault planes at depth and is directly related to the coseismic movement along these planes.

2. The integration of the paleoseismic data sets, nowadays available, recognizes a total of seven distinct $\mathrm{M}$ $6.5+, 2016$ Norcia-type surface faulting earthquakes in the last $\sim 22 \mathrm{kyr}$, including 2016 , on the same fault zones and characterized by a similar amount and style of deformation. Like in 2016, multiple faults splays ruptured with the same individual event.

3. The consistency in age and throw of the correlated events at the five trenches (from this work and from Galli et al., 2019) along the antithetic splays (PRA1 and PRA2) suggests that the NE dipping fault ruptured the surface in the past earthquakes with comparable extent and displacement to that observed in the M 6.5, 2016 Norcia earthquake. Despite the lack of paleoearthquake data on the main fault trace (Mt. Porche-Mt. Argentella), the consistency of the results on the antithetic fault indicates that they are representative for the whole deformation zone of the central portion of the system.

4. The penultimate event that ruptured the VBFS occurred 1,760-1,440 years ago and may well correspond to one of the earthquakes that caused coseismic damage recorded in Rome dated 443 or 484/508 CE. This interpretation is in agreement with that in Galli et al. (2019).

5. The average throw in earlier events along the southernmost synthetic splay is larger than that observed in 2016. Although we cannot exclude the fact that the larger values may include throws from multiple events that occurred too close in time to be individually recognized, we hypothesize that the larger throws of the paleoruptures at this portion of the VBFS possibly reveal the linkage with the southern contiguous fault system, the LMFS. Notwithstanding this linkage, the Amatrice and Norcia earthquakes did not join in a single larger event, and thus, different earthquake rupture scenarios should be also considered for the local hazard assessment analyses. Paleoseismology holds a large potential for defining these alternatives and for implementing segmentation and recurrence models.

Acknowledgments
We thank the Parco Nazionale dei Monti Sibillini, the Comune di Arquata, and Comune di Castel Sant'Angelo sul Nera for their collaboration and for permitting the opening of the trenches. Many thanks to Maria Elvira Speranza and her family, to Giandomenico Di Mattia, and to Sabatino Riccioni for their kindness and for having allowed the trenching of their private lands. To their family names are dedicated the trenches Hope, Matthew, and Curly, respectively. Professional support and high quality excavation service was provided by GEO geotecnica e geognostica srl. We are grateful to the organizing committee of the International Workshop "From 1997 to 2016: Three destructive earthquakes along the central Apennine fault system, Italy (July 19th-22nd 2017)" and to all the participants who visited and discussed our trenches during the field trip. Also thanks to anyone occasionally involved during the trench survey. The development of this research benefited of the Cooperation Agreement between INGV and IRSN. Terrestrial laser scanning (TLS) point cloud of the south wall of the Matthew trench is provided by $\mathrm{L}$. Gregory, $\mathrm{L}$. Wedmore, and K. Mc Caffrey (data available at https://doi.org/10.5069/ G9G15Z03). We thank Kris Vanneste and an anonymous reviewer for their comments and suggestions, which significantly improved this manuscript. Data and materials availability: All data needed to evaluate the conclusions in the paper are present in the paper, in the supporting information, in the cited references, and at https://doi.org/ 10.5281 /zenodo.3355395.
6. The average recurrence of surface faulting events is in the range of 3,360-3,640 years during the last $\sim 22$ kyr. This average interval is longer compared to that of the last $\sim 4 \mathrm{kyr}$, which is 1,220-1,970 years. Assuming that this irregular variation of the earthquake recurrence is due to a natural variability, and not to a bias in the data, the probability that Iev is less than 3,000 years is $\sim 0.6$, with the most likely value close to 2,000 year.

7. A dip-slip rate of $0.26-0.38 \mathrm{~mm} /$ year is estimated for the antithetic fault in the central portion of the VBFS, and it is considered a minimum for the master fault at this location, and a dip-slip value of at least $0.10 \mathrm{~mm} /$ year is obtained for the southernmost portion of the system. Using these values and the morphologic throw of the long-term scarps at the studied fault splays, we inferred a youthful inception of the antithetic and secondary synthetic fault scarp (Middle-Late Pleistocene). Overall, the paleoseismologically and geomorphologically derived Late Pleistocene-Holocene rates of slip well reproduce the trend of the 30 October 2016 net slip and throw, suggesting that the time window exposed in the trenches can be well considered representative for the present fault activity.

This work from integrated paleoseismic data represents the most complete analysis for the study area available so far. Although the reconstructed history suffers from the intrinsic uncertainties belonging to any paleoseismological work, well highlighted also by the 2016 surface faulting sequence (see section 2), these results should be seen as a reference point for further studies to constrain the intrinsic variability in the range and frequency of earthquake sizes caused by the VBFS.

\section{References}

Akcar, N., Tikhomirov, D., Ozkaymak, C., Ivy-Ochs, S., Alfimov, V., Sozbilir, H., et al. (2012). ${ }^{36} \mathrm{Cl}$ exposure dating of paleoearthquakes in the Eastern Mediterranean: First results from the western Anatolian Extensional Province, Manisa fault zone, Turkey. Geological Society of America Bulletin, 124(11-12), 1724-1735. https://doi.org/10.1130/B30614.1

Blumetti, A. M., Di Manna, P., Comerci, V., Guerrieri, L., \& Vittori, E. (2017). Paleoseismicity of the San Demetrio ne' Vestini fault (L'Aquila basin, central Italy). Quaternary International, 451, 129-142. https://doi.org/10.1016/j.quaint.2016.12.039

Bronk Ramsey, C. (2009). Bayesian analysis of radiocarbon dates. Radiocarbon, 51(1), 337-360. https://doi.org/10.1017/ S0033822200033865

Brozzetti, F., Boncio, P., Cirillo, D., Ferrarini, F., Nardis, R., Testa, A., et al. (2019). High-resolution field mapping and analysis of the August-October 2016 coseismic surface faulting (central Italy earthquakes): Slip distribution, parameterization, and comparison with global earthquakes. Tectonics, 38, 417-439. https://doi.org/10.1029/2018TC005305 
Centamore, E., Adamoli, L., Berti, D., Bigi, S., Casnedi, R., Cantalamessa, G., Fumanti, F., Morelli, C., Micarelli, A., Ridolfi, M., \& Salvucci, R. (1992). Carta geologica dei bacini della Laga e del Cellino e dei rilievi carbonatici circostanti (Marche meridionali, Lazio nord-orientale, Abruzzo settentrionale). Scale 1:100,000. Firenze: SELCA

Cheloni, D., de Novellis, V., Albano, M., Antonioli, A., Anzidei, M., Atzori, S., et al. (2017). Geodetic model of the 2016 central Italy earthquake sequence inferred from InSAR and GPS data. Geophysical Research Letters, 44, 6778-6787. https://doi.org/10.1002/ 2017GL073580

Chiaraluce, L., Di Stefano, R., Tinti, E., Scognamiglio, L., Michele, M., Casarotti, E., \& Marzorati, S. (2017). The 2016 central Italy seismic sequence: A first look at the mainshocks, aftershocks, and source models. Seismological Research Letters, 88(3), 757-771. https://doi.org/ $10.1785 / 0220160221$

Chiaraluce, L., Ellsworth, W. L., Chiarabba, C., \& Cocco, M. (2003). Imaging the complexity of an active normal fault system: The 1997 Colfiorito (central Italy) case study. Journal of Geophysical Research, 108(B6), 2294. https://doi.org/10.1029/2002JB002166

Chiaraluce, L., Valoroso, L., Piccinini, D., Di Stefano, R., \& De Gori, P. (2011). The anatomy of the 2009 L'Aquila normal fault system (central Italy) imaged by high resolution foreshock and aftershock locations. Journal of Geophysical Research, 116, B12311. https:/doi. org/10.1029/2011JB008352

Cinti, F. R., Civico, R., Blumetti, A. M., Chiarini, E., la Posta, E., Pantosti, D., et al. (2018). Evidence for surface faulting earthquakes on the Montereale fault system (Abruzzi Apennines, central Italy). Tectonics, 37, 2758-2776. https://doi.org/10.1029/2017TC004780

Cinti, F. R., Pantosti, D., de Martini, P. M., Pucci, S., Civico, R., Pierdominici, S., et al. (2011). Evidence for surface faulting events along the Paganica fault prior to the 6 April 2009 L'Aquila earthquake (central Italy). Journal of Geophysical Research, 116, B07308. https://doi.org/ 10.1029/2010JB007988

Civico, R., Pucci, S., Villani, F., Pizzimenti, L., De Martini, P. M., Nappi, R., \& the Open EMERGEO Working Group (2018). Surface ruptures following the 30 October 2016 Mw6.5 Norcia earthquake, central Italy. Journal of Maps, 14(2), 151-160. https://oi.org/10.1080/ 17445647.2018.1441756

Como, M. (2016). The Colosseum. In Statics of historic masonry constructions. Springer Series in Solid and Structural Mechanics, 5, (pp. 351-389). Cham: Springer. https://doi.org/10.1007/978-3-319-24569-0_8

Cowie, P. A., Roberts, G. P., Bull, J. M., \& Visini, F. (2012). Relationships between fault geometry, slip rate variability and earthquake recurrence in extensional settings. Geophysical Journal International, 189(1), 143-160. https://doi.org/10.1111/j.1365-246X.2012.05378.x

D'Anastasio, E., De Martini, P. M., Selvaggi, G., Pantosti, D., Marchioni, A., \& Maseroli, R. (2006). Short-term vertical velocity field in the Apennines (Italy) revealed by geodetic levelling data. Tectonophysics, 418(3-4), 219-234. https://doi.org/10.1016/j.tecto.2006.02.008

Di Donato, M., Boncio, P., Mataloni, G., Testa, A., Palumbo, D., \& Le Donne, L. (2018). Evidenze di paleodislocazioni cosismiche lungo la faglia di M. Vettore (Italia centrale) rivelate da analisi topografiche di dettaglio della scarpata di faglia su roccia. Extended abstracts of the $37^{\circ}$ GNGTS Congress, Bologna 19-21 November 2018, 46-48.

Di Luccio, F., Ventura, G., Di Giovambattista, R, Piscini, A., \& Cinti, F. R. (2010). Normal faults and thrusts reactivated by deep fluids: The 6 April $2009 \mathrm{Mw}$ 6.3 L'Aquila earthquake, central Italy. Joumal of Geophysical Research, 115, B06315. https://doi.org/10.1029/ 2009JB007 190

EMERGEO Working Group (2016). Coseismic effects of the 2016 Amatrice seismic sequence: First geological results. Annals of Geophysics, 59, 2016. https://doi.org/10.4401/ag-7195

EMERGEO Working Group (2017a). A new photographic dataset of the coseismic geological effects originated by the M5.9 Visso and M6.5 Norcia earthquakes (26th and 30th October 2016, central Italy), Miscellanea INGV,38, 1-114. (http://www.ingv.it/editoria/miscellanea/ 2017/miscellanea38/, last accessed 26 February 2019)

EMERGEO Working Group (2017b). Photographic collection of the coseismic geological effects originated by the 24th August 2016, Amatrice (central Italy) seismic sequence, Miscellanea INGV, 34: 1-114. (http://www.ingv.it/editoria/miscellanea/2017/miscellanea34/, last accessed 26 February 2019)

Fossen, H., \& Rotevatn, A. (2016). Fault linkage and relay structures in extensional settings: A review. Earth-Science Reviews, 154, 14-28. https://doi.org/10.1016/j.earscirev.2015.11.014

Friedrich, A. M., Wernicke, B. P., Niemi, N. A., Bennett, R. A., \& Davis, J. L. (2003). Comparison of geodetic and geologic data from the Wasatch region, Utah, and implications for the spectral character of Earth deformation at periods of 10 to 10 million years. Journal of Geophysical Research, 108(B4), 2199. https://doi.org/10.1029/2001JB000682

Galadini, F., Ceccaroni, E., \& Falcucci, E. (2010). Archaeoseismological evidence of a disruptive Late Antique earthquake at Alba Fucens (central Italy). Bollettino di Geofisica Teorica ed Applicata, 51(2-3), 143-161.

Galadini, F., \& Galli, P. (1999). The Holocene paleoearthquakes on the 1915 Avezzano earthquake faults (central Italy): Implications for active tectonics in the central Apennines. Tectonophysics, 308(1-2), 143-170. https://doi.org/10.1016/S0040-1951(99)00091-8

Galadini, F., \& Galli, P. (2003). Paleoseismology of silent faults in the central Apennines (Italy): The Mt. Vettore and Laga Mts. faults. Annals of Geophysics, 46(5), 815-836. https://doi.org/10.4401/ag-3457

Galadini, F., Galli, P., \& Moro, M. (2003). Paleoseismology of silent faults in the central Apennines (Italy): The Campo Imperatore Fault (Gran Sasso Range Fault System). Annals of Geophysics, 46(5). https://doi.org/10.4401/ag-3456

Galadini, F., Ricci, G., Falcucei, E., \& Panzieri, C. (2018). Archaeoseismological evidence of past earthquakes in Rome (fifth to ninth century A.D.) used to quantify dating uncertainties and coseismic damage. Natural Hazards, 94(1), 319-348. https://doi.org/10.1007/ s11069-018-3390-0

Galli, P., Galadini, F., \& Pantosti, D. (2008). Twenty years of paleoseismology in Italy. Earth Sciences Reviews, 88(1-2), 89-117. https://doi. org/10.1016/j.earscirev.2008.01.001

Galli, P., Galderisi, A., Ilardo, I., Piscitelli, S., Scionti, V., Bellanova, J., \& Calzoni, F. (2018). Holocene paleoseismology of the Norcia fault system (central Italy). Tectonophysics, 745, 154-169. https://doi.org/10.1016/j.tecto.2018.08.008

Galli, P., Galderisi, A., Peronace, E., Giaccio, B., Hajdas, I., Messina, P., et al. (2019). The awakening of the dormant Mt Vettore fault (2016 central Italy earthquake, Mw 6.6). Paleoseismic clues on its millennial silences. Tectonics, $38,687-705$. https://doi.org/10.1029/ $2018 \mathrm{TC} 005326$

Galli, P., \& Molin, D. (2014). Beyond the damage threshold: The historic earthquakes of Rome. Bulletin of Earthquake Engineering, 12(3), 1277-1306. https://doi.org/10.1007/s10518-012-9409-0

Gori, S., Giaccio, B., Galadini, F., Falcucci, E., Messina, P., Sposato, A., \& Dramis, F. (2011). Active normal faulting along the Mt. Morrone south-western slopes (central Apennines, Italy). International Journal of Earth Sciences, 100(1), 157-171. https://doi.org/10.1007/ s00531-009-0505-6

Guidoboni, E. (1989). Catalogo. In E. Guidoboni (Ed.), I terremoti prima del Mille in Italia e nell'area mediterranea, (pp. 574-750). Bologna: SGA. 
Guidoboni, E., Ferrari, G., Mariotti, D., Comastri, A., Tarabusi, G., Sgattoni, G., \& Valensise, G. (2018). CFTI5Med, Catalogo dei Forti Terremoti in Italia (461 a.C.-1997) e nell'area Mediterranea (760 a.C.-1500), Istituto Nazionale di Geofisica e Vulcanologia (INGV). (http://storing.ingv.it/ctti/ctti5/, last accessed 29 May 2019)

Hecker, S., Abrahamson, N. A., \& Wooddell, K. E. (2013). Variability of displacement at a point: Implications for earthquake-size distribution and rupture hazard on faults. Bulletin of the Seismological Society of America, 103(2A), 651-674. https://doi.org/10.1785/ 0120120159

Kuras, O., Beamish, D., Meldrum, P. I., \& Ogilvy, R. D. (2006). Fundamentals of the capacitive resistivity technique. Geophysics, 71(3), G135-G152. https://doi.org/10.1190/1.2194892

Loke, M. H., \& Barker, R. (1996). Rapid least-squares inversion of apparent resistivity pseudosections using a quasi-Newton method. Geophysical Prospecting, 44(1), 131-152. https://doi.org/10.1111/j.1365-2478.1996.tb00142.x

Lucente, F. P., Gori, P. D., Margheriti, L., Piccinini, D., Bona, M. D., Chiarabba, C., \& Agostinetti, N. P. (2010). Temporal variation of seismic ve-locity and anisotropy before the $2009 \mathrm{MW} 6.3$ L'Aquila earthquake, Italy. Geology, 38, 1015-1018. https://doi.org/10.1130/G31463.1

Marzocchi, W., \& Melini, D. (2014). On the earthquake predictability of fault interaction models. Geophysical Research Letters, 41, 8294-8300. https://doi.org/10.1002/2014GL061718

Marzocchi, W., Selva, J., Cinti, F. R., Montone, P., Pierdominici, S., Schivardi, R., \& Boschi, E. (2009). On the occurrence of large earthquakes: New insights from a model based on interacting faults embedded in a realistic tectonic setting. Journal of Geophysical Research, 114, B01307. https://doi.org/10.1029/2008JB005822

Michetti, A. M., Brunamonte, F., Serva, L., \& Vittori, E. (1996). Trench investigations of the 1915 Fucino earthquake fault scarps (Abruzzo, central Italy): Geological evidence of large historical events. Journal of Geophysical Research, 101(B3), 5921-5936. https://doi.org/ 10.1029/95JB02852

Miller, S. A., Collettini, C., Chiaraluce, L., Cocco, M., Barchi, M., \& Kaus, B. J. P. (2004). Aftershocks driven by a high-pressure CO2 source at depth. Nature, 427, 724-727. https://doi.org/10.1038/nature02251

Montone, P., Mariucei, M. T., \& Pierdominici, S. (2012). The Italian present-day stress map. Geophysical Journal International, 189(2), 705-716. https://doi.org/10.1111/j.1365-246X.2012.05391.x

Moro, M., Falcucci, E., Gori, S., Saroli, M., \& Galadini, F. (2016). New paleoseismic data across the Mt. Marine Fault between the 2016 Amatrice and 2009 L'Aquila seismic sequences (central Apennines). Annals of Geophysics, 59(5). https://doi.org/10.4401/ag-7260

Nicol, A., Robinson, R., Van Dissen, R., \& Harvison, A. (2016). Variability of recurrence interval and single-event slip for surface rupturing earthquakes in New Zealand. New Zealand Journal of Geology and Geophysics, 59(1), 97-116. https://doi.org/10.1080/ 00288306.2015 .1127822

Pantosti, D., D'Addezio, G., \& Cinti, F. R. (1996). Paleoseismicity of the Ovindoli-Pezza fault, central Apennines, Italy: A history including a large, previously unrecorded earthquake in the Middle Ages (860-1300 A.D.). Journal of Geophysical Research, 101(B3), 5937-5959. https://doi.org/10.1029/95JB03213

Pierantoni, P., Deiana, G., \& Galdenzi, S. (2013). Stratigraphic and structural features of the Sibillini Mountains (Umbria-Marche Apennines, Italy), Italy. Journal of Geosciences, 132(3), 497-520. https://doi.org/10.3301/IJG. 2013.08

Pizzi, A., Di Domenica, A., Gallovič, F., Luzi, L., \& Puglia, R. (2017). Fault segmentation as constraint to the occurrence of the main shocks of the 2016 Central Italy seismic sequence. Tectonics, 36, 2370-2387. https://doi.org/10.1002/2017TC004652

Pucci, S., de Martini, P. M., Civico, R., Villani, F., Nappi, R., Ricci, T., et al. (2017). Coseismic ruptures of the 24 August 2016, Mw 6.0 Amatrice earthquake (central Italy). Geophysical Research Letters, 44, 2138-2147. https://doi.org/10.1002/2016GL071859

Reimer, P. J., Bard, E., Bayliss, A., Beck, J. W., Blackwell, P. G., Bronk Ramsey, C., et al. (2013). IntCal13 and Marine13 radiocarbon age calibration curves 0-50,000 years cal BP. Radiocarbon, 55(4), 1869-1887. https://doi.org/10.2458/azu_js_rc.55.16947

Robinson, R. (2004). Potential earthquake triggering in a complex fault network: The northern South Island, New Zealand. Geophysical Journal International, 159(2), 734-748. https://doi.org/10.1111/j.1365-246X.2004.02446.x

Robinson, R., Nicol, A., Walsh, J. J., \& Villamor, P. (2009). Features of earthquake occurrence in a complex normal fault network: Results from a synthetic seismicity model of the Taupo Rift, New Zealand. Geophysical Journal International, 114(B12), B12306. https://doi.org/ 10.1029/2008JB006231

Rossi, A., Tertulliani, A., Azzaro, R., Graziani, L., Rovida, A., Maramai, A., et al. (2019). The 2016-2017 earthquake sequence in Central italy: macroseismic survey and damage scenario through the EMS-98 intensity assessment. Bulletin of Earthquake Engineering, 17(5), 2407-2431. https://doi.org/10.1007/s10518-019-00556-W

Salvi, S., Cinti, F. R., Colini, L., D'Addezio, G., Doumaz, F., \& Pettinelli, E. (2003). Investigation of the active Celano-L'Aquila Fault System, Abruzzi (central Apennines, Italy) with combined ground penetrating radar and palaeoseismic trenching. Geophysical Journal International, 155(3), 805-818. https://doi.org/10.1111/j.1365-246X.2003.02078.x

Schwartz, D. P. (2018). Review: Past and future fault rupture lengths in seismic source characterization-The long and short of it. Bulletin of the Seismological Society of America, 108(5A), 2493-2520. https://doi.org/10.1785/0120160110

Scognamiglio, L., Tinti, E., Casarotti, E., Pucci, S., Villani, F., Cocco, M., et al. (2018). Complex fault geometry and rupture dynamics of the MW 6.5, 30 October 2016, central Italy earthquake. Journal of Geophysical Research: Solid Earth, 123, 2943-2964. https://doi.org/ 10.1002/2018JB015603

Tinti, E., Scognamiglio, L., Michelini, A., \& Cocco, M. (2016). Slip heterogeneity and directivity of the ML 6.0, 2016, Amatrice earthquake estimated with rapid finite-fault inversion. Geophysical Research Letters, 43, 10,745-10,752. https://doi.org/10.1002/2016GL071263

Villani, F., Civico, R., Pucci, S., Pizzimenti, L., Nappi, R., De Martini, P. M., \& the Open EMERGEO Working Group (2018). A database of the coseismic effects following the 30 October 2016 Norcia earthquake in Central Italy. Scientific Data, 5(1). https://doi.org/10.1038/sdata.2018.49

Villani, F., Pucci, S., Civico, R., De Martini, P. M., Cinti, F. R., \& Pantosti, D. (2018). Surface faulting of the 30 October 2016 Mw 6.5 central Italy earthquake: Detailed analysis of a complex coseismic rupture. Tectonics, 37, 3378-3410. https://doi.org/10.1029/2018TC005175

Villani, F., \& Sapia, V. (2017). The shallow structure of a surface-rupturing fault in unconsolidated deposits from multi-scale electrical resistivity data: The 30 October $2016 \mathrm{Mw} 6.5$ central Italy earthquake case study. Tectonophysics, 717, 628-644. https://doi.org/10.1016/j. tecto.2017.08.001

Walters, R. J., Gregory, L. C., Wedmore, L. N. J., Craig, T. J., MeCaffrey, K., Wilkinson, M., et al. (2018). Dual control of fault intersections on stop-start rupture in the 2016 Central Italy seismic sequence. Earth and Planetary Science Letters, 500,1-14. https://doi.org/10.1016/j. eps1.2018.07.043

Wedmore, L. N. J., Faure Walker, J. P., Roberts, G. P., Sammonds, P. R., McCaffrey, K. J. W., \& Cowie, P. A. (2017). A 667 year record of coseismic and interseismic Coulomb stress changes in central Italy reveals the role of fault interaction in controlling 
irregular earthquake recurrence intervals. Journal of Geophysical Research: Solid Earth, 122, 5691-5711. https://doi.org/10.1002/ $2017 \mathrm{JB} 014054$

Wedmore, L. N. J., Gregory, L. C., McCaffrey, K. J. W., Goodall, H., \& Walters, R. J. (2019). Partitioned off-fault deformation in the 2016 Norcia earthquake captured by differential terrestrial laser scanning. Geophysical Research Letters, 46, 3199-3205. https://doi.org/ 10.1029/2018GL080858

Wilkinson, M. W. (2017). Near-field fault slip of the 2016 Vettore Mw 6.6 earthquake (central Italy) measured using low-cost GNSS. Scientific Reports, 7(1), 4612. https://doi.org/10.1038/s41598-017-04917-w

\section{References From the Supporting Information}

ISIDe working group (2016). Version 1.0, https://doi.org/10.13127/ISIDe. (http://ent.rm.ingv.it/iside, last accessed 26 February 2019) Rovida, A., Locati, M., Camassi, R., Lolli, B., \& Gasperini, P. (2016). CPTI15, the 2015 version of the Parametric Catalogue of Italian Earthquakes. Istituto Nazionale di Geofisica e Vulcanologia. http://doi.org/10.6092/INGV.IT-CPTI15 